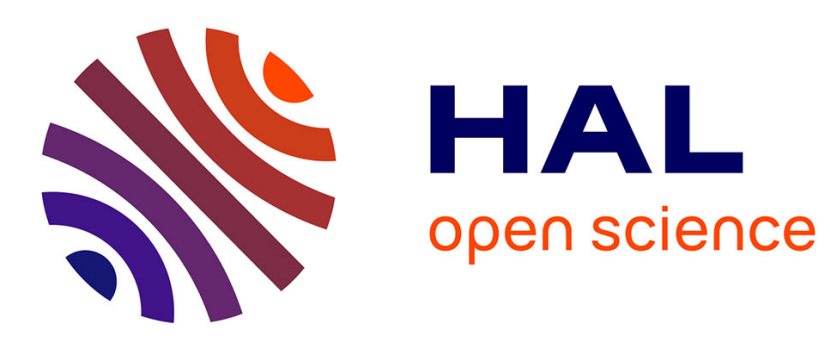

\title{
Inside debt renegotiation: Optimal debt reduction, timing, and the number of rounds
}

Franck Moraux, Florina Silaghi

\section{To cite this version:}

Franck Moraux, Florina Silaghi. Inside debt renegotiation: Optimal debt reduction, timing, and the number of rounds. Journal of Corporate Finance, 2014, 2014 (27), pp.269-295. 10.1016/j.jcorpfin.2014.05.012 . halshs-01024229

\section{HAL Id: halshs-01024229 \\ https://shs.hal.science/halshs-01024229}

Submitted on 12 Oct 2014

HAL is a multi-disciplinary open access archive for the deposit and dissemination of scientific research documents, whether they are published or not. The documents may come from teaching and research institutions in France or abroad, or from public or private research centers.
L'archive ouverte pluridisciplinaire HAL, est destinée au dépôt et à la diffusion de documents scientifiques de niveau recherche, publiés ou non, émanant des établissements d'enseignement et de recherche français ou étrangers, des laboratoires publics ou privés. 


\title{
Inside debt renegotiation: Optimal debt reduction, timing, and the number of rounds
}

\author{
Franck Moraux ${ }^{\mathrm{a}}$, Florina Silaghi ${ }^{\mathrm{a}, *}$ \\ ${ }^{a}$ Université de Rennes 1, 11, Rue Jean Macé, 35000, Rennes, France
}

\begin{abstract}
This paper develops a model of debt renegotiation in a structural framework that accounts for taxes, bankruptcy costs and renegotiation costs. To our knowledge, all the previous work on debt renegotiation implies an infinite number of renegotiations. This feature preempts the analysis of the optimal number of renegotiations. We address this drawback by incorporating fixed renegotiation costs in a model of multiple renegotiations, hence obtaining a small finite number of renegotiations. Simple analytical formulae are derived for debt and equity, as well as implicit formulae for the coupon reduction, as a result of a backward recursive technique. The results show that the optimal number of renegotiations, the size and the dynamics of the coupon reductions depend critically on the bargaining power of the claimants. Testable empirical implications regarding multiple costly renegotiations are drawn.
\end{abstract}

Keywords: Debt renegotiation, Debt pricing, Strategic contingent claim analysis JEL: G30, G32, G33, G13

\footnotetext{
${ }^{*}$ Corresponding author. Tel.: +33 (0)2 232378 08; fax: +33 (0)2 23237834 .

Email addresses: franck.moraux@univ-rennes1.fr (Franck Moraux), florina.silaghi@univ-rennes1.fr (Florina Silaghi)
} 
"The basic idea was to make debt relief acceptable to commercial bank creditors by offering a smaller but much safer payment stream in exchange for the original claim that clearly could not be serviced in full.", Sturzenegger and Zettelmeyer (2007) ${ }^{1}$

\section{Introduction}

Although there exists an abundant literature on debt renegotiation, to our knowledge, all previous work implies an infinite number of renegotiations. This feature preempts the analysis of the optimal number of renegotiations. In this paper, we address this drawback by incorporating fixed renegotiation costs in a model of multiple renegotiations, hence obtaining a small finite number of renegotiations.

Debt renegotiation is important and quite common, both at corporate and sovereign level. It exists in formal legal contexts and in private workouts. ${ }^{2,3}$ It also appears in very closely related situations such as breach of covenants, ${ }^{4}$ LBO restructuring and corporate bond clawbacks. ${ }^{5}$

Preliminary thoughts on debt renegotiation are offered by Leland (1994) in the eighth section of his famous article. A rigorous analysis of debt renegotiation is then presented in strategic debt service models (SDS hereafter), as in the papers of Anderson and Sundaresan (1996), Mella-Barral and Perraudin (1997) and Fan and Sundaresan (2000), to name only a few. SDS consists of arbitrary "take-it-or-leave-it" offers (from the equity holder to creditors or from creditors to the equity holder) that result in a temporary reduction in the coupon. Mella-Barral (1999), Hege and Mella-Barral (2000) and Lambrecht (2001) on the other hand, model debt renegotiation in the form of permanent coupon reductions. ${ }^{6}$

In a SDS setting, the firm is financed with a perpetual debt whose coupon is paid in full as long as an underlying state variable (assets value or output price) remains above a certain renegotiation threshold. When this threshold is reached from above for the first time, the firm starts paying a lower coupon and retakes the full coupon payment as soon as the firm recovers, i.e. when the state variable reaches the threshold from below. The initial coupon level can be reduced and restored many times with no constraint. This unconstrained view to proceed has been proved to have a clear advantage for finding analytical formulae. But this stylized way has some clear drawbacks too.

First, the number of renegotiations is possibly infinite, which of course is not realistic. Second, we consider that SDS models emphasize effects of temporary missed interest payments rather than effects of the permanent solution debt and equity holders may look for. Third, in some SDS models, the firm can strategically avoid bankruptcy through an infinite number of renegotiations, which is not the case in the real world.

Mella-Barral (1999) proposes a model with permanent coupon reductions in which selling the assets of the firm becomes preferable to continuing operating it. It therefore addresses two of the drawbacks of SDS models. However, in this model each time the state variable reaches a new minimum, the coupon will be reduced by an infinitesimal amount. This continuous way of reducing the coupon implies the firm could potentially have an infinite number of renegotiations in a finite period of time. Hence, this model also suffers from the main drawback of SDS models in the sense that the number of renegotiations is potentially infinite.

\footnotetext{
${ }^{1}$ It is worth having a look at the rich economic literature on sovereign debt renegotiation as this issue has been extensively studied compared to corporate debt renegotiation. The clear-cut description of the Brady plan (a plan for sovereign debt restructuring at the end of the 1980s in Latin America) made by Sturzenegger and Zettelmeyer (2007) captures the essence of our model. Suter (1992) reveals that for interwar sovereign defaults, interest payments suffered an average haircut of $34 \%$ and face values were reduced by $23 \%$. For recent evidence on sovereign debt renegotiation see Bai and Zhang (2012).

${ }^{2}$ Empirical studies demonstrate that private workouts are quite often considered by firms in financial distress. Gilson et al. (1990), for instance, find that about half of the 169 firms they consider resolve distress through private workouts. A very strong incentive is that costs of private workouts are significantly lower than formal bankruptcy costs (see again Gilson et al., 1990, Franks and Torous, 1989 and Bris et al., 2006).

${ }^{3}$ Favara et al. (2012) show that equity risk is smaller in countries in which the bankruptcy code favors formal debt renegotiation.

${ }^{4}$ See Garleanu and Zwiebel (2009) for an analysis of debt covenants renegotiation.

${ }^{5}$ For recent evidence on corporate bond clawbacks see Daniels et al. (2013).

${ }^{6}$ Debt renegotiation may lead however to other kinds of restructuring such as debt equity swaps and maturity extension (see Fan and Sundaresan, 2000 and Longstaff, 1990 respectively). Debt renegotiation with multiple lenders is analyzed by Dumitrescu (2007), Hackbarth et al. (2007) and Hege and Mella-Barral (2005). Chen (2003) and Shibata and Tian (2010, 2012) study debt renegotiation in the presence of asymmetric information.
} 
In this paper, we follow Mella-Barral (1999) by modeling debt renegotiation in the form of permanent coupon reductions. However, we believe it is important to account for frictions that prevent infinite renegotiations. We thus incorporate a fixed renegotiation cost. This allows us to answer an important question regarding what the optimal number of renegotiations should be. To the best of our knowledge, we are the first to address this question. We present a new continuous time model of debt renegotiation in which we derive and investigate the effects of finite costly renegotiations on equity, debt, firm value, capital structure and the optimal number of renegotiations.

We consider a firm financed by equity and a perpetual debt. Following Leland (1994), the equity holder decides optimally when to stop paying the coupons and defaults at an endogenously determined bankruptcy threshold. At any point in time between debt issuance and bankruptcy time, the party that has all bargaining power can propose renegotiation in the form of a permanently reduced coupon, while keeping the other party indifferent at its reservation value. $^{7}$ The party with all bargaining power optimally decides the renegotiation thresholds, the coupon reductions and the optimal number of renegotiations in order to maximize its claim value.

We analyze two polar cases in which either the equity holder or the creditors have all bargaining power. Moreover, we incorporate a parameter that captures the bargaining power of each party. This allows us to derive implications and discuss the solutions of our model for a general distribution of bargaining power.

We first present a benchmark model of one single costless renegotiation. When the equity holder has all bargaining power, she proposes renegotiation at Leland's default threshold, maintaining debt value constant. ${ }^{8}$ The later the equity holder renegotiates, the higher the coupon reduction she will be able to obtain from creditors. As in Leland (1994), debt value is a hump-shaped function of the coupon, which means there exists a coupon for which debt value is maximized. When the assets value deteriorates, the initial coupon agreed with the creditors is above the coupon that maximizes debt value, which implies that the equity holder is paying a high unsustainable coupon. Reducing the coupon would actually increase debt value (as long as the reduced coupon is above a minimum acceptable coupon that maintains debt value constant).

When creditors have all bargaining power, they also want to renegotiate as late as possible, at the same renegotiation threshold. Regarding the coupon reduction, we show that the coupon should be reduced at least to $67 \%$ of the initial value, and at most to $27 \%$ of the initial coupon level (for our baseline case). Any coupon value above $67 \%$ is Pareto dominated, as we could further reduce it and improve both the value of debt and equity. The coupon cannot be reduced beyond $27 \%$ as creditors would refuse renegotiation. The exact size of the coupon depends on the bargaining power of claimants. To our knowledge, this is the first paper to provide a range for the optimal coupon reduction. Additionally, we find that renegotiation increases total firm value and that the renegotiation surplus can be shared among claimants according to their bargaining power.

In the general framework that allows for multiple costly renegotiations we obtain a series of new interesting results. When the equity holder has all bargaining power, we have a "cascade" of coupon reductions. Each time the assets value reaches Leland's default threshold corresponding to the current coupon value, the coupon will be significantly reduced. At each renegotiation stage the firm is downsized in the same proportion. Given the renegotiation costs, the equity holder will only renegotiate a very small number of times.

When creditors have all bargaining power, renegotiation occurs at Leland's default threshold as well. However, the coupon reductions and the optimal number of renegotiations are quite different. If creditors anticipate a high number of renegotiations, they will start by only slightly reducing the coupon at the first renegotiation stage. As they reach later renegotiation stages, they will concede higher coupon reductions. If the total number of renegotiations is low, the coupon reduction will be substantial even in the first stage. Compared to the equity holder, creditors renegotiate more often and offer smaller coupon reductions.

These results are derived under the main assumption that the party that has the bargaining power suffers the renegotiation costs. ${ }^{9}$ We verify the robustness of our results in an extension, where we analyze the renegotiation

\footnotetext{
${ }^{7}$ From a theoretical perspective, renegotiation is equivalent to a debt-for-debt swap. Evidences from the field (see Roberts and Sufi, 2009 and Roberts, 2010) show that renegotiations are much more common than new loans.

${ }^{8} \mathrm{~A}$ coupon reduction has a direct negative effect on debt value, and an indirect positive effect through default probability. Reducing the coupon decreases the probability of default and hence the present value of liquidation costs. Creditors accept renegotiation if the indirect positive effect dominates.

${ }^{9}$ Previous contributions, such as Garleanu and Zwiebel (2009) and Mella-Barral and Perraudin (1997), make the same assumption. Although this might seem at first counter-intuitive, in general the party that has the bargaining power takes all the renegotiation surplus. Thus the other party cannot suffer the renegotiation cost. For more details, see section Section 3.
} 
process under an alternative assumption that the equity holder always suffers the renegotiation costs.

The closest papers in the literature to our model are Mella-Barral (1999) and Lambrecht (2001). As them, we model debt renegotiation in the form of permanent coupon reductions. Our main contribution is that we allow for fixed renegotiation costs and analyze the optimal number of renegotiations. Although this is mathematically challenging, by using a backward recursive approach and proof by induction, we succeed in obtaining analytical formulae for debt and equity, and computing the optimal renegotiation threshold, coupon reduction and number of renegotiations. As Mella-Barral (1999) points out, his model is robust to the introduction of proportional renegotiation costs. With fixed renegotiation costs however, the results are very different: we obtain "lumpy" and finite coupon reductions as opposed to infinite infinitesimal reductions. Finally, a last difference with respect to Mella-Barral (1999) concerns liquidation. While in his model the firm is eventually liquidated because its value in the hands of outsiders is higher than the continuation value, in our model the firm is liquidated because the equity holder no longer wishes to pay the coupon, and high renegotiation costs prevent further renegotiation. For the polar case of a single costless renegotiation with the equity holder having all bargaining power we obtain the model of Lambrecht (2001). For zero renegotiation costs, we obtain similar results to Mella-Barral (1999).

The small number of renegotiations we find is in line with the empirical evidence. According to the latter, for both formal reorganizations and private workouts, the total number of renegotiations for the same firm/loan is small, with higher numbers for the latter. Few firms undertake a second formal reorganization through Chapter 11 after a first debt restructuring: Gilson (1997) finds a percentage of only 33\%, LoPucki and William C. (1993), as well as Hotchkiss (1995) find 32\%, and Alderson and Betker (1999) 24\%. As for private workouts, Roberts (2010) finds an average of 4 private renegotiations for the typical loan in his sample conditional on renegotiation (and an unconditional average of 2.6).

In practice renegotiations are often private agreements between two parties, thus data is many times unavailable. A theoretical model is then welcome to fill this gap. We derive a series of novel testable empirical implications regarding multiple costly renegotiations. These predictions could motivate further empirical research using the few data available.

The rest of the paper is organized as follows. Section 2 describes our financial setup and valuation of financial claims. Section 3 develops the solution of the renegotiation process under our main assumption that the party that has the bargaining power suffers the renegotiation costs. Section 4 examines the optimal number of renegotiations. In Section 5 we analyze the renegotiation process under the alternative assumption that the equity holder always suffers the renegotiation costs. Numerical simulations are discussed in Section 6, while empirical implications are derived in Section 7. Finally, Section 8 concludes.

\section{Financial setup and valuation}

This section describes first the continuous-time financial setup we use, introduces our model of debt renegotiation and then presents the valuation of financial claims. Our setting follows Leland (1994). Financial markets are perfect, ${ }^{10}$ efficient and complete and trading takes place continuously. There exists a riskless asset paying a known and constant interest rate denoted by $r$. There are no transaction costs. Let us now consider a firm that is financed by equity and a consol debt only. Initially, creditors enjoy a coupon whose value is denoted by $c$. The firms' assets value is observable by all agents and is correctly described under the objective probability measure by a geometric Brownian motion:

$$
d V_{t}=\mu V_{t} d t+\sigma V_{t} d W_{t},
$$

where $W=\left(W_{t}\right)_{t}$ is a standard Brownian motion, $\mu$ and $\sigma$ represent the drift and volatility terms, respectively. If ever the firm's assets value falls below a certain threshold level, say $V_{B}$, the firm goes bankrupt. ${ }^{11}$ The firm pays income taxes at a rate $\tau$, at least until bankruptcy. In case of liquidation, a fraction of the assets value, denoted by $\alpha(0 \leq \alpha \leq 1)$

\footnotetext{
${ }^{10}$ Perfection here does not mean that there is no liquidation cost.

${ }^{11}$ Throughout the paper, default, bankruptcy and liquidation occur simultaneously as differentiating them is out of the scope of the paper. See Bruche and Naqvi (2010), François and Morellec (2004) and Moraux (2002), for a discussion on this. This bankruptcy threshold is an endogenously determined one.
} 
is lost and the absolute priority rule strictly applies. This means that creditors must be fully repaid before the equity holder can receive something.

In the absence of renegotiation, we know how to price equity, unprotected debt, tax shields, bankruptcy costs and the firm as a whole when the equity holder can decide to stop paying the coupon (see Leland, 1994). The price of unprotected debt is e.g. given by:

$$
d\left(V, c, V_{B}\right)=\frac{c}{r}\left(1-\left(\frac{V}{V_{B}}\right)^{-X}\right)+(1-\alpha) V_{B}\left(\frac{V}{V_{B}}\right)^{-X}
$$

whereas that of the equity is:

$$
e\left(V, c, V_{B}\right)=\left\{V+\frac{c}{r} \tau\left(1-\left(\frac{V}{V_{B}}\right)^{-X}\right)-\alpha V_{B}\left(\frac{V}{V_{B}}\right)^{-X}\right\}-d\left(V, c, V_{B}\right),
$$

where the term in brackets in Eq. (3) stands for the total value of the firm. Here, the constant $X$ is given by $X=2 r / \sigma^{2}$ and the value of the firm's assets $V$ is higher than the default threshold $V_{B}=\frac{(1-\tau) c}{r} \frac{X}{1+X}=\frac{(1-\tau) c}{r+0.5 \sigma^{2}} \equiv V_{B}(c)$, which is endogenously chosen by the equity holder. Note that $V_{B}$ is the optimal default threshold in the absence of renegotiation and it solves the smooth-pasting condition $\left.\frac{\delta e\left(V, c, V_{B}\right)}{\delta V}\right|_{V=V_{B}}=0$.

In the presence of renegotiation, the equity holder aims at reducing the initial coupon $c$ to a lower payment once or several times. For simplicity and in order to provide intuition we start by presenting the case of one costless renegotiation. Later on we will generalize the setting to multiple (finite) costly renegotiations.

\subsection{One costless renegotiation}

Let us assume that renegotiation is costless and that the two parties only renegotiate once. Renegotiation consists of reducing the initial coupon $c$ to a lower payment of $c^{\prime}$. Hence the equity holder pays the initial coupon until the firm's assets value reaches a certain renegotiation threshold $V_{S}$ (if ever). At $V_{S}$ the party that has the bargaining power proposes renegotiation and a lower coupon $c^{\prime}$ will be paid until a new (postponed) default threshold $V_{B}^{\prime}$ is reached. ${ }^{12}$ One has $V_{B}^{\prime} \leq V_{S} \leq V$, where $V$ is the initial assets value. ${ }^{13}$ The following proposition then applies.

Proposition 1. For all $V_{B}^{\prime} \leq V_{S} \leq V$

(i) The debt value is given by:

$$
D\left(V, c, V_{S}, c^{\prime}, V_{B}^{\prime}\right)=\frac{c}{r}\left(1-\left(\frac{V}{V_{S}}\right)^{-X}\right)+\frac{c^{\prime}}{r}\left(1-\left(\frac{V_{S}}{V_{B}^{\prime}}\right)^{-X} \frac{V}{V_{S}}\right)^{-X}+(1-\alpha) V_{B}^{\prime}\left(\frac{V}{V_{B}^{\prime}}\right)^{-X}
$$

(ii) The equity value is given by:

$$
\begin{aligned}
E\left(V, c, V_{S}, c^{\prime}, V_{B}^{\prime}\right) & =\left\{V+\frac{c}{r} \tau\left(1-\left(\frac{V}{V_{S}}\right)^{-X}\right)+\frac{c^{\prime}}{r} \tau\left(1-\left(\frac{V_{S}}{V_{B}^{\prime}}\right)^{-X}\right)\left(\frac{V}{V_{S}}\right)^{-X}-\alpha V_{B}^{\prime}\left(\frac{V}{V_{B}^{\prime}}\right)^{-X}\right\}-D\left(V, c, V_{S}, c^{\prime}, V_{B}^{\prime}\right) \\
& =V-(1-\tau) \frac{c}{r}\left(1-\left(\frac{V}{V_{S}}\right)^{-X}\right)-(1-\tau) \frac{c^{\prime}}{r}\left(1-\left(\frac{V_{S}}{V_{B}^{\prime}}\right)^{-X}\right)\left(\frac{V}{V_{S}}\right)^{-X}-V_{B}^{\prime}\left(\frac{V}{V_{B}^{\prime}}\right)^{-X} .
\end{aligned}
$$

Proof of Proposition 1. See Appendix A.

\footnotetext{
${ }^{12}$ We highlight that we distinguish between two different situations: no renegotiation, which corresponds to Leland's case in which the firm defaults at $V_{B} \equiv V_{B}(c)$ and renegotiation (the model proposed in this paper) in which the firm renegotiates at $V_{S}$ and defaults at a new default threshold $V_{B}^{\prime}$.

${ }^{13}$ Notice that the new default threshold $V_{B}^{\prime}$ accounts for the existence of renegotiation, thus it will be lower or equal to $V_{S}$.
} 
Other highlighting equivalent expressions to Eqs. (4) and (5) are respectively:

$$
\begin{gathered}
D\left(V, c, V_{S}, c^{\prime}, V_{B}^{\prime}\right)=\frac{c}{r}\left(1-\left(\frac{V}{V_{S}}\right)^{-X}\right)+d\left(V_{S}, c^{\prime}, V_{B}^{\prime}\right)\left(\frac{V}{V_{S}}\right)^{-X}, \\
E\left(V, c, V_{S}, c^{\prime}, V_{B}^{\prime}\right)=\left(V-\frac{(1-\tau) c}{r}\right)+\left\{e\left(V_{S}, c^{\prime}, V_{B}^{\prime}\right)-\left(V_{S}-\frac{(1-\tau) c}{r}\right)\right\}\left(\frac{V}{V_{S}}\right)^{-X} .
\end{gathered}
$$

Eq. (6) reveals that, until the first hitting time of $V_{S}$, creditors receive (for sure) the initial coupon flow. Eq. (7) highlights that the debtor owns the firm's assets minus the coupon flow paid to creditors (net of tax). As soon as the renegotiation threshold is hit, stakeholders simply swap their initial share for a new Leland-type equity claim, which depends on the new reduced coupon.

The post renegotiation default thresholds $\left(V_{B}^{\prime}\right)$ is determined strategically by the equity holder, just as she chooses the default one in Leland (1994). Since the coupon change is unique and permanent, the equity just after the single reorganization is that studied by Leland (1994): his findings therefore apply and the optimal default threshold is $V_{B}^{\prime}=$ $V_{B}\left(c^{\prime}\right)=\frac{(1-\tau) c^{\prime}}{r} \frac{X}{1+X}=\frac{(1-\tau) c^{\prime}}{r+0.5 \sigma^{2}}$. The post-renegotiation endogenous default threshold $V_{B}^{\prime}$ is therefore a consequence of the choice of $c^{\prime}$. We analyze the optimal choice of the reduced coupon in Section 3.

\subsection{Multiple costly renegotiations}

We now generalize the previous framework to allow for multiple costly renegotiations. Assume that each time the coupon is renegotiated a fixed cost $K$ is incurred. Fixed renegotiation costs prevent firms from infinitely renegotiating their debt, leading to a finite number of lumpy renegotiations rather than an infinite number of very small and continuous renegotiations. ${ }^{14}$ Quite similar to this concern, Fischer et al. (1989) consider in their study of dynamic recapitalization policies that costs of recapitalization prevent a firm from adjusting its capital structure continuously.

Actually, costs of renegotiation, either reputational or administrative, could matter for both parties for different reasons. On the one hand, the firm's reputation and its value might be strongly affected as the private workout becomes common knowledge to the stakeholders (clients, suppliers, employees, etc.). As a result, part of the renegotiation cost could be of a reputational nature consisting in a loss in the borrower's trustworthiness. At the same time, creditors' reputation might suffer as current renegotiation sends a "debtor-friendly" signal to other firms which might want the same concessions. On the other hand, renegotiation also implies some administrative costs, such as legal expenses and the opportunity cost of time. Indeed, when analyzing the renegotiation of debt covenants, Garleanu and Zwiebel (2009) interpret renegotiation costs as administrative costs.

Both types of costs could be suffered by both parties. Who suffers the renegotiation costs also depends on the distribution of the bargaining power. We analyze first the two polar cases of creditors having all bargaining power and the equity holder having all the power. Following Mella-Barral and Perraudin (1997) and Garleanu and Zwiebel (2009), we assume that the renegotiation cost will be suffered by the party that has all bargaining power. ${ }^{15}$ Although this might seem at first counter-intuitive, this assumption is motivated by the fact that in general, the party that has all bargaining power realizes all the bilateral gain from renegotiation. As Garleanu and Zwiebel (2009) argue, under an alternative specification for bargaining power, it would not matter who paid these costs. Under this assumption, we interpret renegotiation costs as administrative costs, including legal costs and the opportunity cost of time. Since the costs are suffered by the party that has the bargaining power, they can also be interpreted as the cost of making a take-it-or-leave-it-offer.

Nevertheless, our model differs from the literature in the sense that we have finite lumpy coupon reductions rather than infinite, very small and continuous reductions. This will have an impact on the distribution of the renegotiation surplus, and will imply that the equity holder always takes a part of the gain. Thus, the creditors, even when they have

\footnotetext{
${ }^{14}$ If the cost incurred at renegotiation were proportional to the increase in firm value as opposed to fixed, a fraction of the renegotiation surplus for instance, then, as noted by Mella-Barral (1999), the number of renegotiations would be infinite.

${ }^{15}$ In their model of temporary coupon reductions, Mella-Barral and Perraudin (1997) add an extension in which they consider the inclusion of renegotiation costs. Regarding who suffers these costs they say "under equityholder offers [...] the entire incidence of the renegotiation costs is on the equityholders", while under "debtholders offers [...] the incidence will be entirely on [...] the bondholders".
} 
all bargaining power, do not realize all the gain, and in fact the equity holder would be able to suffer the renegotiation costs. This is why we will analyze in Section 5 the model under the assumption that the equity holder always suffers the renegotiation costs, irrespective of who has the bargaining power. Under this assumption, our preferred interpretation for the nature of the renegotiation costs is the reputational one. One could argue that reputation costs are borne by the equity holder because a collapse in trustworthiness is a loss for her, regardless of whether she has the bargaining power or not.

For our main model we follow the literature and make the simplifying assumption that the party that has all bargaining power suffers the renegotiation costs. As we will see later on, under this assumption the model is more tractable and we obtain a larger number of analytical results, without affecting our main conclusions on the optimal number of renegotiations. ${ }^{16}$

Hereafter, we will refer to the assumption that the party that has the bargaining power suffers the renegotiation cost as the main assumption, and to the assumption that the equity holder always suffers the cost as the alternative assumption.

Given that under the main assumption our preferred interpretation for the renegotiation costs is administrative, we think that a fixed cost is a reasonable choice. ${ }^{17}$ It is sensible to expect legal expenses or the opportunity cost of time to remain constant at future renegotiation stages. However, it might be argued that there is a "learning effect", that the legal procedure is already known at the second round and maybe renegotiation could be sped up, so that costs are reduced. Moreover, since under the alternative assumption costs are more likely to be of a reputational nature, we could expect them to decrease with the number of rounds. Consequently, we provide numerical simulations for geometrically decreasing costs as well in Section $6 .{ }^{18}$

We assume for now that the total number of renegotiations made by the firm is an exogenous integer number $n$. We will endogenize it and the parties will optimally choose the total number of renegotiations in Section 4 . Let $c_{i}$ be the reduced coupon value set at the renegotiation stage $i$, where $1 \leq i<n$. The firm will pay this coupon from the moment the assets value has reached the renegotiation threshold $V_{S_{i}}$ and until the assets value reaches the next renegotiation threshold $V_{S_{i+1}}$. For $i=n$ the coupon $c_{n}$ will be paid from the last renegotiation threshold $V_{S_{n}}$ until the liquidation threshold $V_{B_{n}}$, at which the firm is liquidated.

The following proposition gives the valuation of the firm's securities for a given number of renegotiations $n$ and a fixed renegotiation cost $K$ :

Proposition 2. For all $n \in \mathbb{Z}$, with $n \geq 2$

(i) The debt value is given by:

$$
\begin{aligned}
D(V, c, n) & =\frac{c}{r}\left(1-\left(\frac{V}{V_{S_{1}}}\right)^{-X}\right)+\sum_{i=1}^{n-1} \frac{c_{i}}{r}\left(1-\left(\frac{V_{S_{i}}}{V_{S_{i+1}}}\right)^{-X}\right)\left(\frac{V}{V_{S_{i}}}\right)^{-X} \\
& +\frac{c_{n}}{r}\left(1-\left(\frac{V_{S_{n}}}{V_{B_{n}}}\right)^{-X}\right)\left(\frac{V}{V_{S_{n}}}\right)^{-X}+(1-\alpha) V_{B_{n}}\left(\frac{V}{V_{B_{n}}}\right)^{-X}-l K \sum_{i=1}^{n}\left(\frac{V}{V_{S_{i}}}\right)^{-X} .
\end{aligned}
$$

(ii) The equity value is given by:

$$
\begin{aligned}
E(V, c, n) & =V-(1-\tau) \frac{c}{r}\left(1-\left(\frac{V}{V_{S_{1}}}\right)^{-X}\right)-\sum_{i=1}^{n-1}(1-\tau) \frac{c_{i}}{r}\left(1-\left(\frac{V_{S_{i}}}{V_{S_{i+1}}}\right)^{-X}\right)\left(\frac{V}{V_{S_{i}}}\right)^{-X} \\
& -(1-\tau) \frac{c_{n}}{r}\left(1-\left(\frac{V_{S_{n}}}{V_{B_{n}}}\right)^{-X}\right)\left(\frac{V}{V_{S_{n}}}\right)^{-X}-V_{B_{n}}\left(\frac{V}{V_{B_{n}}}\right)^{-X}-(1-l) K \sum_{i=1}^{n}\left(\frac{V}{V_{S_{i}}}\right)^{-X},
\end{aligned}
$$

where $l=1$ if creditors have all bargaining power, and $l=0$ if the equity holder has all bargaining power.

\footnotetext{
${ }^{16}$ Indeed, when renegotiation costs are incurred by the party with no bargaining power, the model loses tractability since the coupon reductions depend on the renegotiation costs, and most of the results cannot be derived analytically.

${ }^{17}$ Garleanu and Zwiebel (2009) also assume renegotiation costs to be fixed administrative costs.

${ }^{18}$ Accounting for geometrically decreasing costs is very simple from an analytical point of view in our valuation formulae.
} 


\section{Proof of Proposition 2. See Appendix A.}

The interpretation of the above equations is similar to that for the case of one single renegotiation. The difference is that renegotiation is now costly. This implies a fixed cost of $K$ is incurred at each renegotiation stage by the party that has all bargaining power.

These equations are thus valid for two extreme cases, one in which the creditors have all bargaining power and one in which the equity holder has all bargaining power. We argue in Subsection 3.3 that similar valuation formulae can be obtained for an intermediate bargaining power. The difference will be that the renegotiation cost is shared by the two parties according to their bargaining power.

The valuation formulae we present depend on the value of the reduced coupons and the renegotiation thresholds. These will be optimally chosen by the two parties according to their bargaining power. In the next section we study the optimal choice of the coupons and renegotiation thresholds for the two extreme situations in which one party has all bargaining power. We then generalize this for all bargaining powers.

\section{Solving the renegotiation problem}

We now solve for the renegotiation problem, that is, we determine optimally the reduced coupons and the renegotiation thresholds. As before, we take an exogenous initial coupon value $c$ and an exogenous number of renegotiations $n$. These will be optimally determined in the following sections.

We analyze first the case in which the equity holder has all bargaining power, and second the case in which the creditors have all bargaining power. Finally, we discuss the renegotiation problem for the entire range of bargaining power.

As Mella-Barral (1995) and Lambrecht (2001) argue, once the assets value drops below the liquidation threshold (Leland's $V_{B}(c)$ ), the equity holder may be unwilling to continue to inject cash into the firm, especially if they fear that workouts in the future might be unsuccessful. We therefore make the following assumption:

Assumption 1. For all $i \in\{1,2, \ldots, n\}$ we have that $V_{B}\left(c_{i}\right) \leq V_{S_{i}} \leq V$.

In order to find the optimal renegotiation thresholds we will use a backwards recursive approach. We will start solving for the optimal coupon reduction and optimal renegotiation threshold at the last renegotiation stage. Then, given this optimal choice at the last stage, we will move one period backwards and compute the optimal choice at the stage before the last. Continuing in this way, we always solve for the optimal renegotiation threshold and coupon reduction at one stage, given that all the following thresholds and coupons have been optimally chosen.

We know that at the last renegotiation stage $n$ (when the assets value reaches $V_{S_{n}}$ ), we are in a Leland-type setting. For a given value of the last reduced coupon $c_{n}$, the equity holder chooses optimally the liquidation threshold which will be given by $V_{B_{n}}=V_{B}\left(c_{n}\right)$. We now move one stage backwards, at the $n-1$ renegotiation, when the assets value equals $V_{S_{n-1}}$. At this stage, for a given value of $c_{n-1}$, the parties have to choose the optimal renegotiation threshold $V_{S_{n}}$ and the optimal reduced coupon $c_{n}$, knowing that the firm will be liquidated at $V_{B}\left(c_{n}\right)$. We move one period backwards at $n-2$, i.e., the assets value equals $V_{S_{n-2}}$. For a given value of $c_{n-2}$, the parties choose the optimal renegotiation threshold $V_{S_{n-1}}$ and the optimal reduced coupon $c_{n-1}$, knowing that the coupon will be further reduced when the assets value reaches $V_{S_{n}}$ and that the firm will be liquidated at $V_{B}\left(c_{n}\right)$. Proceeding in this way backwards, we arrive at $V$, the initial assets value. For a given value of the initial coupon $c$, the parties have to decide the optimal renegotiation threshold $V_{S_{1}}$ and the reduced coupon $c_{1}$. In doing this, they take into account the fact that the firm will optimally renegotiate $n-1$ times in the future, and that the future renegotiation thresholds and reduced coupons are a function of $V_{S_{1}}$ and $c_{1}$.

\subsection{Equity holder has all bargaining power}

To convince creditors to accept a coupon reduction, the equity holder proposes them a new coupon such that the value of their new claim is at least as big as the current value of their debt (which represents their reservation value). Creditors can always refuse any change. If the value of their debt remains the same, creditors are indifferent between accepting and rejecting the offer in terms of utility. However, they can expect the new lower debt service to 
be financially easier to sustain. ${ }^{19}$ When the equity holder has all bargaining power she will offer a coupon that leaves creditors exactly indifferent between accepting or rejecting the offer.

Given that $V_{S_{i}} \geq V_{B}\left(c_{i}\right)$, the reservation value of the creditors is the debt value in the absence of renegotiation (with full coupon payments). This is because if creditors refuse renegotiation, it is optimal for the equity holder to continue paying the full coupon (equity is positive above $V_{B}\left(c_{i}\right)$ ), and not to default (the equity holder would get zero in default). At each renegotiation stage $i$, the new coupon $c_{i}$ has to satisfy the following condition:

$$
D\left(V_{S_{i}}, c_{i}, n-i\right)=d\left(V_{S_{i}}, c_{i-1}, V_{B}\left(c_{i-1}\right)\right) .^{20}
$$

This equation implies that the debt value with the new reduced coupon, given that the debt will be further renegotiated $n-i$ times, is equal to the debt value in the absence of renegotiation (that is, if the firm continues paying the prevailing coupon $\left.c_{i-1}\right)$. Such an equation can only be solved numerically. For the last renegotiation stage $(i=n)$, this equation becomes $d\left(V_{S_{n}}, c_{n}, V_{B}\left(c_{n}\right)\right)=d\left(V_{S_{n}}, c_{n-1}, V_{B}\left(c_{n-1}\right)\right)$. We know from Leland that debt value in the absence of renegotiation is a hump-shaped function of the coupon value. Therefore, for a given $c_{n-1}$ we can find $c_{n}<c_{n-1}$ such that the debt value stays constant, as shown in the left panel of Fig. $1 .{ }^{21}$ This is due to the fact that a coupon reduction has two opposite effects on the debt value which exactly cancel out at $c_{n}$ : the direct negative effect and the indirect positive effect of reducing the default probability.

The above condition makes creditors indifferent, because renegotiations are innocuous in the sense they have no special impacts on their debt (compared to Leland's benchmark case). A critical consequence of this is that the time zero debt value with renegotiations is exactly equal to that derived by Leland with no renegotiation. Corporate debt pricing with multiple renegotiations is therefore not a problem here, but it should be clear that the probability of default is no longer the same. Potentially it may be far more complex than predicted by the standard setting.

The following result gives an important insight on how the equity value relates to the renegotiation thresholds.

Lemma 1. For all $i \in\{2, \ldots, n\}$, we have $\frac{\partial E\left(V_{S_{i-1}}, c_{i-1}, n-i+1\right)}{\partial V_{S_{i}}}<0, V_{S_{i}}=V_{B}\left(c_{i-1}\right)$, and for $i=1$ we have $\frac{\partial E(V, c, n)}{\partial V_{S_{1}}}<0$, $V_{S_{1}}=V_{B}(c)$.

Proof of Lemma 1. The renegotiation threshold has two opposite effects on equity value: a positive direct effect and a negative indirect effect through its impact on the reduced coupon. The reasoning is as follows: on the one hand the equity holder would like to renegotiate as soon as possible in order to obtain a coupon reduction. On the other hand, the later she renegotiates, the higher the coupon reduction she obtains. We show in Appendix A that this latter effect dominates. Equity is indeed a decreasing function of $V_{S_{i}}$ and the optimal renegotiation threshold at each stage is Leland's default threshold.

At any renegotiation stage, the equity value is a decreasing function of the renegotiation threshold. The lemma therefore reveals that the equity holder should postpone the renegotiation as long as possible so as to maximize the coupon reduction. Let us consider the last but one renegotiation stage $(i=n-1)$, where the equity holder has to choose optimally $V_{S_{n}}$ for a given $c_{n-1}$. Her optimal choice of $V_{S_{n}}$ will also determine $c_{n}$. She sets $V_{S_{n}}$ so as to maximize equity value, keeping creditors indifferent at their reservation value. Because $E\left(V_{S_{n-1}}, c_{n-1}, 1\right)$ is a decreasing function of $V_{S_{n}}$, she will postpone the renegotiation as long as possible and initiate it at the standard liquidation threshold i.e. $V_{S_{n}}:=V_{B_{n-1}}=V_{B}\left(c_{n-1}\right)$. Knowing this final optimal renegotiation threshold, the final reduced coupon $c_{n}$ can be computed as a proportion of $c_{n-1}$. The following result reveals how the coupon is reduced.

\footnotetext{
${ }^{19} \mathrm{We}$ assume without loss of generality that whenever creditors are indifferent they will accept renegotiation. A reason for this is that, in anticipation of rejection, the equity holder can always slightly increase the coupon such that the creditors strictly prefer acceptance.

${ }^{20}$ Notice that this is highly different from what is usually assumed in the literature. Creditors are usually posited indifferent between accepting or rejecting the offer because the debt value is equal to the liquidation value. Notice also that at renegotiation creditors receive a lower coupon. However, by reducing the coupon, creditors avoid the bankruptcy costs and decrease the probability of a future default. Overall, creditors benefit from a coupon reduction.

${ }^{21}$ For this equation to have a solution, we need $c_{n-1}>C_{\max }\left(V_{S_{n}}\right)$, that is, the prevailing coupon has to be above the coupon that maximizes debt value at this assets value. This condition will be satisfied at the optimal $V_{S_{n}}$.
} 
Lemma 2. For all renegotiations $i \in\{1,2, \ldots, n\}$ we have $\frac{c_{i}}{c_{i-1}}=\gamma$ with $c_{0}=c$ the initial coupon and $\gamma$ a real positive number strictly lower than one satisfying:

$$
\frac{\gamma\left(1-\gamma^{X}\right)(X+1)}{(1-\alpha)(1-\tau) X}+\gamma^{X+1}=1
$$

Proof of Lemma 2. See Appendix A.

Each time the coupon is reduced, the new coupon is a fixed proportion of the previous one. This proportion $\gamma$ depends on the interest rate, tax rate, volatility and bankruptcy costs. We can then rewrite the cascade of coupons $c_{i}=\gamma^{i} c$ and simplify Eq. (9). For the specific case of one single costless renegotiation $(n=1$ and $K=0)$, we recover the model of Lambrecht (2001). Since renegotiation is costly in our model, debt restructuring does not take place continuously, like in Mella-Barral (1999). In his costless renegotiation model, the equity holder starts reducing the coupon as soon as possible and the coupon is gradually reduced (by an infinitesimal amount) each time the firm's assets value reaches a new minimum. In our model, given that the equity holder suffers a cost at each renegotiation, she will limit the number of renegotiations while maximizing the effect of reducing the coupon, i.e. renegotiating as late as possible to obtain the highest coupon reduction possible.

\subsection{Creditors have all bargaining power}

When creditors have all bargaining power, they choose the renegotiation thresholds and the coupon reduction in order to maximize debt value, subject to the constraint that the equity value under renegotiation is at least as high as the equity value with no renegotiation. This constraint is not binding however because the equity price is zero in the absence of renegotiation. Because the debt value is a hump-shaped function of the coupon value, creditors choose the one that maximizes debt value at the contemporaneous renegotiation threshold (see panel b) of Fig. 1). More formally, creditors set, at each renegotiation stage $i$, the coupon $c_{i}$ to $C_{\text {max }}$ - the coupon that maximizes debt value when $V=V_{S_{i}}$ (given that the firm will undergo $n-i$ additional renegotiations). This condition can be written as follows:

$$
D\left(V_{S_{i}}, c_{i}, n-i\right)=\beta_{\text {max }_{i}} d\left(V_{S_{i}}, c_{i-1}, V_{B}\left(c_{i-1}\right)\right),
$$

where $\beta_{\text {max }_{i}}=\frac{D\left(V_{S_{i}}, C_{\text {max }_{i}}, n-i\right)}{d\left(V_{S_{i}}, c_{i-1}, V_{B}\left(c_{i-1}\right)\right)}$.

The following lemmas summarize our results.

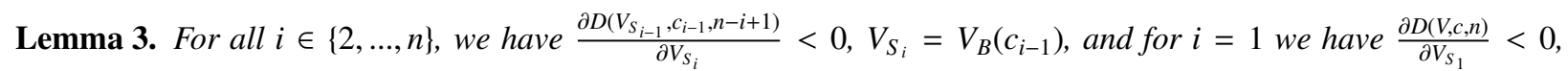
$V_{S_{1}}=V_{B}(c)$.

Proof of Lemma 3. A formal proof is provided in Appendix A. The intuition is as follows. The creditors want to renegotiate as late as possible, in order to receive the full coupon the longest time possible. However, the equity holder is not willing to continue paying the full coupon beyond Leland's default threshold. Hence, creditors propose renegotiation at the point at which the equity holder would liquidate the firm.

Lemma 4. For all $i \in\{1,2, \ldots, n\}$ we have that $\frac{c_{i}}{c_{i-1}}=\phi_{i}$, where $\phi_{i}$ satisfies:

$$
\phi_{i}=\left[(X+1)\left(1-\sum_{k=i+1}^{n} \phi_{k}\left(1-\phi_{k}^{X}\right)\left(\mathbb{1}_{\{i+1 \leq k-1\}} \prod_{j=i+1}^{k-1} \phi_{j}^{X+1}+\mathbb{1}_{\{i+1>k-1\}}\right)\right)-(1-\alpha)(1-\tau) X \prod_{k=i+1}^{n} \phi_{k}^{X+1}\right]^{-1 / X},
$$

$\forall i \in\{1,2, \ldots, n-1\}$ and $\phi_{n}=[(X+1)-(1-\alpha)(1-\tau) X]^{-1 / X}, c_{0}=c$

Proof of Lemma 4. See Appendix A.

When creditors have all bargaining power, the coupon at each renegotiation stage will be a proportion of the previous coupon. However, this proportion will not be constant, as in the case of equity holder having the entire bargaining power. It can be shown moreover that $\phi_{1}>\phi_{2}>\ldots>\phi_{n-1}>\phi_{n}>\gamma$. Consequently, $\frac{c_{1}}{c}>\frac{c_{2}}{c_{1}}>\ldots>\frac{c_{n}}{c_{n-1}}$. 
That is, the creditors reduce the coupon gradually and the coupon reduction (in relative terms) increases with the number of renegotiations. Interestingly, the coupon reduction at the last renegotiation stage (described by $\phi_{n}$ ) is always the same, irrespective of the number of renegotiations. This is not the case for the coupon reductions at the previous stages. The higher the number of renegotiations, the smaller the coupon reduction at the first stage. When creditors anticipate a high number of renegotiations, they will only reduce the coupon by a small amount in the first renegotiation stage. ${ }^{22}$

Comparing the coupon reductions when creditors have all bargaining power with the coupon reductions when the equity holder has all bargaining power, we can say that $\phi_{n}>\gamma$. This implies that as expected, at each renegotiation stage, the coupon reduction is much higher when the equity holder has all bargaining power.

Comparing to Mella-Barral (1999), we observe that in this model creditors choose to renegotiate as late as possible, just like in Mella-Barral (1999). Nevertheless, while in his paper debt restructuring takes place continuously and the coupon is gradually reduced, in our paper renegotiation happens in a discrete manner, for a finite number of times, since renegotiation is costly.

\subsection{Intermediate values of bargaining power}

We have analyzed so far two extreme situations in which one party has all bargaining power. We now allow for any distribution of the bargaining power between the two parties. We claim that when the parties have intermediate bargaining power, the coupon will be reduced at each renegotiation stage such that the following condition is satisfied:

$$
D\left(V_{S_{i}}, c_{i}, n-i\right)=\beta_{i} d\left(V_{S_{i}}, c_{i-1}, V_{B}\left(c_{i-1}\right)\right),
$$

where $1 \leq \beta_{i} \leq \beta_{\text {max }_{i}}$.

For $\beta_{i}=1$ we obtain the case of the equity holder having all bargaining power Eq. (10), while for $\beta_{i}=\beta_{\text {max }_{i}}$, we obtain the case of the creditors having all bargaining power Eq. (12). As a result, the reduced coupon will be higher than the coupon the equity holder would choose, and lower than the coupon the creditors would choose. Its actual value within this range will depend on $\beta$. One could interpret $\beta$ as a proxy for the bargaining power of creditors. When $\beta=1$, creditors have zero bargaining power as they obtain no surplus from renegotiation. As $\beta$ increases, the bargaining power of creditors increases. Actually their share of the renegotiation surplus increases, until it reaches a maximum. Debt being a hump-shaped function of the coupon level, there exists a maximum value that debt after renegotiation can take, which corresponds to a coupon value equal to $C_{\max }$.

Consider first the case in which $\beta=1$. This implies that debt value stays constant at renegotiation, and that the equity holder captures all the surplus from renegotiation. Let us denote the new coupon obtained in this case by $c_{\min }^{\prime}$. This coupon corresponds to the maximum coupon reduction possible at renegotiation. Any further reduction of the coupon is not possible, since the creditors will not accept any coupon below $c_{\text {min }}^{\prime}$. At the opposite extreme we have the case in which $\beta=\beta_{\text {max }}$, in which the creditors obtain the highest possible increase in their debt value. ${ }^{23}$ Let us denote by $c_{\text {max }}^{\prime}$ the corresponding coupon value. We argue that this matches the minimum coupon reduction at renegotiation. Any coupon in the interval $\left(c_{\text {max }}^{\prime}, c\right)$ would be Pareto dominated, as a decrease in the coupon would make both the creditors and the equity holder better off. Therefore, the coupon has to be reduced at least until $c_{\text {max }}^{\prime}$. We have thus provided a range for the new coupon: $c^{\prime} \in\left[c_{\text {min }}^{\prime}, c_{\text {max }}^{\prime}\right]$. See Fig. 1 for an illustration.

Regarding the renegotiation threshold, since both the creditors and the equity holder want to renegotiate at Leland's default threshold at each stage, we conclude that when the bargaining power is shared between the two parties, renegotiation will take place at the same renegotiation threshold. The following proposition summarizes our results for all the range of bargaining power:

Proposition 3. For all $\beta_{i} \in\left[1, \beta_{\text {max }_{i}}\right]$ we have: $V_{S_{i}}=V_{B_{i-1}}$, for $i \in\{1,2, \ldots, n\}$, where $V_{B_{0}}=V_{B}(c)$.

Proof of Proposition 3. The proof results directly from Assumption 1 and Lemmas 1 and 3.

\footnotetext{
${ }^{22}$ We provide a numerical example in Subsection 6.4.

${ }^{23}$ Note that this surplus is equal to the firm value minus $(1-\alpha) V_{S}$, which is higher than $\alpha V_{S}$ due to the existence of tax shields. In particular, the firm value is higher than the assets value due to the tax advantage of debt. By renegotiating, one saves not only the liquidation costs, but also the future tax benefits.
} 


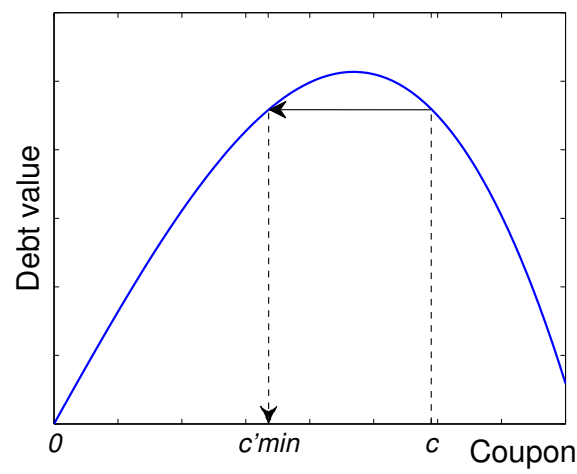

a) Maximum coupon reduction

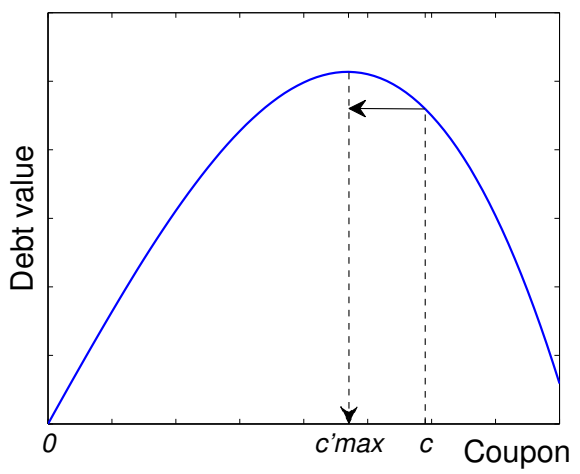

b) Minimum coupon reduction

Figure 1: Coupon Reduction Range. Debt value as a function of the coupon for two different levels of the bargaining power. Panel a): the initial coupon $c$ will be reduced at most until a new coupon $c_{\text {min }}^{\prime}$ (in this case the equity holder has all bargaining power). Panel b): the initial coupon $c$ will be reduced at least until a new coupon $c_{\max }^{\prime}$ (in this case creditors have all bargaining power).

\section{Optimal number of renegotiations}

As before, we analyze the optimal number of renegotiations for two polar cases in which one party has all bargaining power.

\subsection{Equity holder has all bargaining power}

When the equity holder has all bargaining power, she will choose to renegotiate at Leland's default threshold and to reduce the coupon in the same proportion at each renegotiation stage. This essentially corresponds to downsizing the firm in the same proportion each time the renegotiation threshold is reached. We can then express the equity value recursively. Let $E^{0}$ denote the equity value as given by Eq. (9) for $K=0$, that is net of renegotiation costs. We have that:

$$
E^{0}(V, c, n+1)=E^{0}(V, c, n)+E^{0}\left(V_{S_{n+1}}, c_{n+1}, 0\right)\left(\frac{V}{V_{B_{n}}}\right)^{-X},
$$

where $V_{S_{n+1}}=V_{B_{n}}$ and $c_{n+1}=c_{n} \gamma$.

Each time we add a new renegotiation the equity value (net of renegotiation costs) increases by $E^{0}\left(V_{S_{n+1}}, c_{n+1}, 0\right)$ (current value). Given that at each renegotiation stage a cost $K$ is incurred, the equity holder will renegotiate as long as the renegotiation surplus exceeds the renegotiation costs. Hence, the optimal number of renegotiations is given by:

$$
n^{*}=\max \left\{i \in \mathbb{N} ; E^{0}\left(V_{S_{i}}, c_{i}, 0\right) \geq K\right\} .
$$

Of course, the higher the renegotiation costs, $K$, the lower the optimal number of renegotiations, $n^{*}$. We present numerical examples regarding the optimal number of renegotiations in Section 6.

\subsection{Creditors have all bargaining power}

When creditors have the entire bargaining power, they reduce the coupon in a different proportion at each renegotiation stage. The higher the number of renegotiations, the lower is the first coupon reduction. Consequently, we cannot use the same recursive technique as in the previous subsection, in order to compute the optimal number of renegotiations. This is because we cannot nest the debt value with $n+1$ renegotiations into the debt value with $n$ renegotiations.

The optimal number of renegotiations will be chosen by creditors in order to maximize their debt value:

$$
n^{*}=\underset{i}{\arg \max } D(V, c, i) .
$$

Numerical examples regarding the optimal number of renegotiations are presented in Section 6. 


\section{Extension: The equity holder always suffers the cost}

We now analyze the renegotiation process under the assumption that the equity holder always suffers the renegotiation costs, irrespective of the distribution of the bargaining power.

The polar case of the equity holder having all bargaining power does not change, since it is still the equity holder who suffers the costs. We thus focus on the polar case of creditors having all bargaining power and the equity holder suffering the renegotiation costs.

As before, the creditors would like to set the reduced coupon to the coupon that maximizes debt value at the contemporaneous renegotiation threshold, $C_{\max }$. However, their choice is now constrained: the surplus that the equity holder obtains from renegotiation has to be at least as high as the renegotiation cost, otherwise she would refuse renegotiation. When this constraint is satisfied, i.e. the equity surplus under a reduced coupon $C_{\text {max }_{i}}$ is greater than the renegotiation cost $K$, the reduced coupon is $C_{\text {max }_{i}}$.

If this condition is not satisfied, the creditors are willing to decrease the coupon further below $C_{\text {max }}$, as long as their new debt value is above the debt value in the absence of renegotiation. This means that there are two possibilities. If the equity surplus for the reduced coupon that maintains debt value constant $\left(c_{\min }^{\prime}\right.$ in panel a) of Fig. 1) is below the renegotiation cost, renegotiation will not be possible. The creditors would not accept to reduce the coupon below that limit and the equity holder would not accept to pay the renegotiation cost, since it exceeds her surplus. If on the contrary, the surplus gained by the equity holder for the minimum coupon acceptable by the creditors exceeds the cost, then renegotiation is possible. The optimal reduced coupon chosen by the creditors is the one that makes the equity holder indifferent between renegotiating or not (the new coupon is such that the equity surplus is equal to the renegotiation cost).

To summarize, at each renegotiation stage the creditors either choose $C_{\text {max }_{i}}$, the coupon that maximizes debt value, if the equity surplus for this coupon covers the cost, or otherwise they choose the coupon that makes the equity holder indifferent between renegotiating or not. Let us call this coupon $C_{K_{i}}$, the coupon at stage $i$ for which the equity surplus just equals the renegotiation cost, $K$.

Regarding the optimal renegotiation threshold, we obtain as before the following result:

Lemma 5. For all $i \in\{2, \ldots, n\}$, we have $\frac{\partial D\left(V_{S_{i-1}}, c_{i-1}, n-i+1\right)}{\partial V_{S_{i}}}<0, V_{S_{i}}=V_{B}\left(c_{i-1}\right)$, and for $i=1$ we have $\frac{\partial D(V, c, n)}{\partial V_{S_{1}}}<0$, $V_{S_{1}}=V_{B}(c)$.

Proof of Lemma 5. If creditors choose $C_{m a x_{i}}$ at all stages, the proof is the same as for Lemma 3. If $C_{K_{i}}$ is chosen at some stage, given the dependence of the reduced coupon on the renegotiation costs, the model becomes quite complicated and loses tractability. Therefore we cannot provide a complete analytical solution in this case. However, numerical simulations show that the debt value is decreasing in the renegotiation threshold and therefore the optimal renegotiation threshold is Leland's default threshold. An analytical argument is given in Appendix A.

It is worth noticing that at each renegotiation stage, the current renegotiation threshold will be lower than the previous one, since the coupon has been reduced. This imposes a certain pattern in the coupon reductions. It can be shown that if at a renegotiation stage, the optimally reduced coupon makes the equity holder be indifferent between renegotiating or not $\left(C_{K_{i}}\right)$, at all the following renegotiation stages, the optimal reduced coupon will be chosen in the same manner. That is, it is not possible to chooses a coupon $C_{\max }$ at a given stage, if at a previous stage a coupon that makes the equity holder indifferent has been chosen.

We can therefore have three different "cascades" of coupon reductions depending on the size of the renegotiation costs and the initial coupon value. First, the creditors can choose $C_{\text {max }_{i}}$ at all renegotiation stages. This case is identical with the one presented in Subsection 3.2. Second, the creditors can choose $C_{K_{i}}$ at all renegotiation stages. Third, the reduced coupon could be $C_{\text {max }_{i}}$ for the first $j$ stages, and $C_{K_{i}}$ for the following $n-j$ stages.

We can characterize analytically the coupon reduction resulting in the first two cases: ${ }^{24}$

Lemma 6. The optimal coupon reduction is as follows:

\footnotetext{
${ }^{24}$ For the third case, where we have both the coupon $C_{\max }$ and the coupon $C_{K_{i}}$, it is not possible to characterize analytically the relative coupon reduction. This is because the relative coupon reduction depends on the initial value of the coupon for an optimal reduced coupon of $C_{K_{i}}$.
} 
1. If the creditors choose the coupon that maximizes debt value at all renegotiation stages we have: for all $i \in$ $\{1,2, \ldots, n\}, \frac{c_{i}}{c_{i-1}}=\phi_{i}$, where $\phi_{i}$ satisfies Eq. (13).

2. If the creditors choose the coupon that makes the equity holder indifferent at all renegotiation stages we have: for all $i \in\{1,2, \ldots, n\}, \frac{c_{i}}{c_{i-1}}=\phi_{i}$, where $\phi_{i}$ satisfies

$$
X-\frac{K}{c_{i-1}} \frac{r(X+1)}{1-\tau}=\phi_{i}(X+1)-\phi_{i}^{X+1}
$$

Proof of Lemma 6. See Appendix A.

The optimal coupon reduction that makes the equity holder indifferent between renegotiating or not, depends on the value of the initial coupon and also on the renegotiation costs.

Corollary 1. When creditors choose at all stages the optimal coupon such that the equity holder is indifferent between renegotiating or not $\left(C_{K_{i}}\right)$ we have:

1. $\frac{\partial \phi_{i}}{\partial c_{i-1}}>0$, the relative coupon reduction $\left(1-\phi_{i}\right)$ decreases with the initial coupon level.

2. $\frac{\partial \phi_{i}}{\partial K}<0$, the relative coupon reduction $\left(1-\phi_{i}\right)$ increases with the renegotiation costs $K$.

Therefore we will have a different relative coupon reduction at each stage. Of course, this reduction will be larger the higher the renegotiation costs (so that the equity surplus is large enough to cover the renegotiation costs).

The optimal number of renegotiations is chosen by the creditors in order to maximize their debt value as in Subsection 4.2 .

\subsection{Comparison: the party that has the power suffers the cost versus the equity holder suffers the cost}

We can now compare our results under the assumption that the party that has the bargaining power suffers the renegotiation costs with those under the assumption that the equity holder always suffers the cost. For the polar case of the equity holder having all bargaining power, the results are identical.

For the case in which the creditors have all bargaining power, we obtain the same renegotiation threshold, which is equal to Leland's default threshold. The coupon reduction could be different however. If under the second assumption, parameters are such that $C_{\max _{i}}$ is not chosen at all stages, the coupon reductions are different: while under the first assumption, the relative reduction does not depend on the initial coupon level, nor on the renegotiation costs, under the second one it does. The sharing of the renegotiation surplus is also different. Under the first assumption, the equity holder always wins a surplus although creditors have all bargaining power. Under the second one, if the creditors choose $C_{K_{i}}$ at all stages, the creditors take all the surplus and keep the equity holder indifferent at all stages.

Regarding the number of renegotiations, we will show in the following section that under both assumptions we obtain very similar numbers of renegotiations. Consequently, our initial simplifying assumption following the literature, that the party that has the bargaining power suffers the renegotiation costs, is not essential. Although in our model the equity holder captures a part of the surplus, and thus she would be able to pay the renegotiation costs, our main conclusions about a small finite optimal number of renegotiations are not affected, as we will see below.

\section{Numerical analysis}

We now study numerical implications of our model on the default and renegotiation decisions, firm value, capital structure and the number of renegotiations. Regarding parameter values, we choose orders of magnitude similar to those assumed by previous models of debt renegotiation, in order to facilitate comparison between models. For our baseline case, we set the riskless interest rate to 6\% (as Leland, 1994 and Mella-Barral and Perraudin, 1997 did), the tax rate to $35 \%$, volatility to $25 \%$ (both as in Leland, 1994 and Fan and Sundaresan, 2000), bankruptcy costs to 40\% (Mella-Barral and Perraudin, 1997 chose 20\%, while Leland, 1994 chose 50\%) and we consider a coupon rate of $7 \%$. Without loss of generality, we set the initial assets value equal to 100 . Our baseline case parameter values are presented in Table 1. These parameter values are used in all the tables and figures presented in this paper, unless specified otherwise. 
Table 1: Parameter values for the baseline case

\begin{tabular}{cc}
\hline Parameter & Value \\
\hline$V$ & 100 \\
$r$ & $6 \%$ \\
$\tau$ & $35 \%$ \\
$\sigma$ & $25 \%$ \\
$\alpha$ & $40 \%$ \\
$c$ & $7 \%$ \\
\hline
\end{tabular}

In order to better understand the renegotiation mechanism in this paper, we start by providing a numerical analysis for the case of one costless renegotiation. We discuss the renegotiation outcome, capital structure and the renegotiation surplus. Finally, we analyze the case of many costly renegotiations and provide a discussion on the optimal number of renegotiations.

\subsection{Renegotiation outcome}

We start by examining the outcome of renegotiation at different levels of initial leverage of the firm for one costless renegotiation. Table 2 illustrates the variables of interest for coupon rates varying from 5 to $9 \%$. We present as well two special coupon rates that correspond to the optimal leverage and to the firm's debt capacity respectively in the Leland (1994) model, i.e. $C^{*}$ that maximizes the value of the firm and $C_{\max }$ which maximizes the debt value respectively, as defined by Leland. ${ }^{25}$ The variables we focus on are: the renegotiation threshold $V_{S}$ (which coincides with the initial bankruptcy threshold, $V_{B}$ ), a proxy for the probability of renegotiation (the present value of $\$ 1$ to be obtained conditional on renegotiation) and the range for the optimal reduced coupon $c_{\min }^{\prime}$ and $c_{\max }^{\prime}$.

Table 2: Numerical results of the baseline case

\begin{tabular}{cccccc}
\hline Results & $c=5 \%$ & $c=7 \%$ & $c=9 \%$ & $C^{*}=9.27 \%$ & $C_{\max }=9.37 \%$ \\
\hline$V_{S}=V_{B}$ & 35.62 & 49.86 & 64.11 & 66.03 & 66.75 \\
$\left(V / V_{S}\right)^{-X}$ & 0.14 & 0.26 & 0.43 & 0.45 & 0.46 \\
$c_{\min }^{\prime}$ & 1.37 & 1.91 & 2.46 & 2.53 & 2.56 \\
$c_{\max }^{\prime}$ & 3.34 & 4.67 & 6.01 & 6.19 & 6.26 \\
\hline
\end{tabular}

As shown in Table 2, the renegotiation threshold varies from 36 to 67 when we vary the coupon rate from 5\% to the coupon corresponding to the firm's debt capacity of $9.37 \%$. The higher is the coupon they have to pay, the less is the equity holder willing to continue running the firm at this coupon level. The renegotiation probability increases with the coupon level, reaching almost $50 \%$ for a coupon as high as $9 \%$. In all the cases the coupon is reduced at most to $27 \%$ and at least to $67 \%$ of the initial coupon value. ${ }^{26}$ The results suggest that it is precisely because of the huge decrease in coupon that the equity holder obtains at this renegotiation threshold that she chooses to pay the full coupon until reaching $V_{B}$, and does not renegotiate earlier. An earlier renegotiation would imply a smaller decrease in the coupon value.

Fig. 2 illustrates the maximum and the minimum coupon reduction for different values of volatility and bankruptcy costs. We can see that for low volatility levels the coupon range is tight, while as volatility increases this range for the new coupon widens. The coupon will be reduced at least to $86 \%$ of the initial coupon level and at most to $54 \%$ for $\sigma=0.1$ and $\alpha=0.1$. For very risky firms, with $\sigma=0.5$ and $\alpha=0.9$, the coupon is reduced at least to $46 \%$ and at most to $3 \%$ of the initial level. Of course, these are extreme values, but they serve for an illustrative purpose.

\footnotetext{
${ }^{25}$ Note that the optimal coupon and the coupon that corresponds to the firm's debt capacity in this model are in general different from those from Leland's model.

${ }^{26}$ As mentioned previously, the relative coupon reduction does not depend on the initial coupon level.
} 


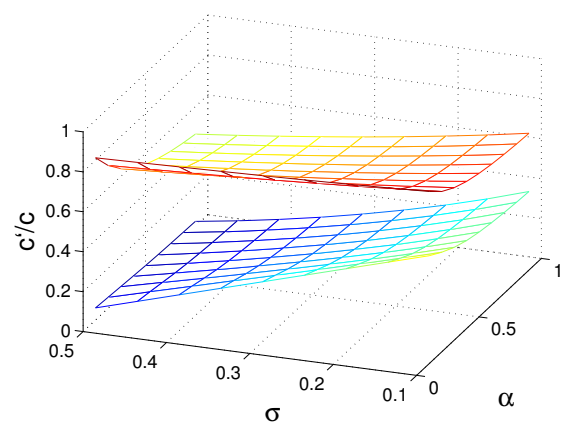

Figure 2: Maximum versus minimum coupon reduction (one costless renegotiation). Relative coupon value $c^{\prime} / c$ as a function of business ( $\sigma$ ) and financial risk $(\alpha)$. The upper surface represents the minimum coupon reduction, where creditors have all bargaining power. The bottom surface represents the maximum coupon reduction, where the equity holder has all bargaining power and the coupon is reduced to the minimum value accepted by creditors.

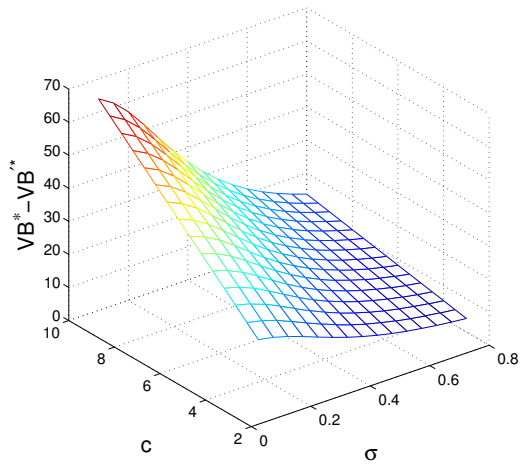

a) Difference in default thresholds

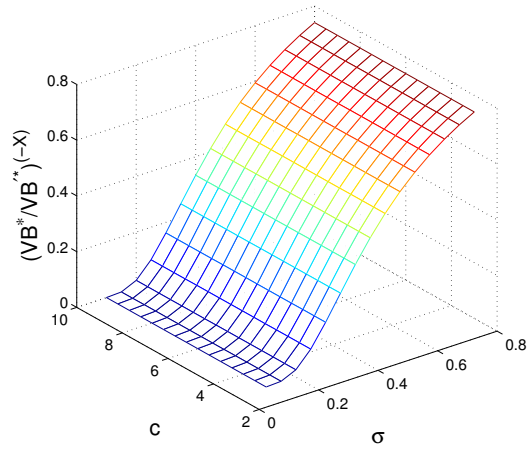

b) Proxy for default probability at $V_{S}$

Figure 3: Extra life due to renegotiation (one costless renegotiation). The plots are presented as a function of the initial coupon $c$ and volatility $\sigma$, given by two distinct measures. In panel a) the distance between the Leland default threshold $V_{B}$ and the post-renegotiation default threshold $V_{B}^{\prime}$ is plotted. Panel b) represents the present value (at renegotiation, when the asset value equals $V_{B}$ ) of $\$ 1$ to be obtained conditional on default post-renegotiation, when the asset value reaches $V_{B}^{\prime}$.

We finally offer further insights on the renegotiation's outcome and effects in Fig. 3, for the case of the maximum coupon reduction. We provide two distinct measures of the "extra life" that the firm obtains through renegotiation: the difference between the two default thresholds and a proxy for the probability of default at renegotiation. ${ }^{27}$ The difference between the two default thresholds plotted in panel a) of Fig. 3 is logically a linear increasing function of $c$ for a given volatility (as $c^{\prime}$ is proportional to $c$ ). For a given coupon level, this distance is decreasing in volatility. The proxy for the default probability plotted in panel b) increases with volatility. Of course, the lower this probability is, the higher the extra life of the firm.

\subsection{Optimal capital structure}

We now study the impact of renegotiation on debt, equity, and firm value, as well as on the optimal capital structure at time 0 . We plot in Fig. 4 debt, equity and firm value for Leland's model (panel a)) and for our model with a single costless renegotiation, the case of maximum coupon reduction with $\beta=1$ (panel b)). As shown in Fig. 4 (panel b)), in this model debt is a hump-shaped function of the coupon, and equity is a U-shaped function of the coupon. Debt

\footnotetext{
${ }^{27}$ This is not exactly the default probability, as it includes the discount factor. It is in fact the present value (at renegotiation) of $\$ 1$ to be obtained conditional on default post-renegotiation.
} 
value in our model is equal to Leland (1994)'s for $\beta=1$, so logically we obtain similar results. Nevertheless, whereas Leland finds that equity is decreasing in the coupon rate, we obtain a U-shaped equity value. This is the consequence of the renegotiation process: the higher is the coupon, the more likely renegotiation becomes and the higher will be the increase in equity due to renegotiation. It turns out that at high (enough) levels of coupon this effect dominates the negative effect found by Leland (1994). ${ }^{28}$ The total firm value is hump-shaped and it reaches its maximum at a $C^{*}$ that is above the one from Leland (1994). Nevertheless, our model predicts lower leverage ratios than Leland's model. This is due to the fact that firm value is higher in our model, which leads to lower leverage ratios. This negative effect dominates the positive effect that the higher optimal coupon has on leverage.

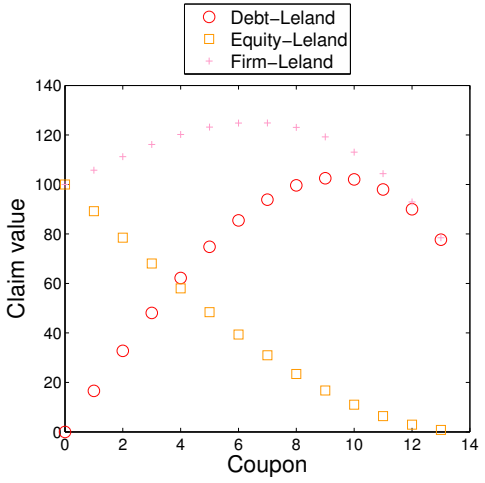

a) Leland



b) This model

Figure 4: Capital structure at inception. Leland's model is presented in panel a), while our model with a single costless renegotiation in panel b). Debt, equity and firm values at time 0 are plotted as a function of the coupon for $\beta=1$, equity holder has all bargaining power.

\subsection{Renegotiation surplus}

Panel a) of Fig. 5 overlaps the debt, equity and firm value derived in this model (with one single costless renegotiation) for $\beta=1$ with the ones obtained by Leland (1994), in order to highlight the added value of renegotiation. We can notice first of all that renegotiation is worthwhile, as the firm value in the presence of renegotiation is higher. Secondly, the extra value obtained through renegotiation is not shared at all among stakeholders, the equity holder captures everything, and creditors get nothing.

Panel b) of Fig. 5 shows the sharing of the renegotiation surplus between creditors and the equity holder for $\beta=\beta_{\text {max }}$. Even when the creditors receive the maximum surplus from renegotiation, they do not capture the whole surplus. Thus, the equity holder's gain from renegotiation is still positive, as the gains of the creditors are limited by $\beta_{\max }$.

Note however, that the renegotiation surplus (the pie shared) is not the same in the two situations as the new coupon differs. Which of the two surpluses is higher depends on the trade-off between tax benefits and bankruptcy costs. Fig. 6, panel a), illustrates the percentage increase in firm value due to renegotiation for the case $\beta=1 .^{29}$ We can notice that renegotiation increases firm value by up to $12 \% .{ }^{30}$ Panel b) shows the difference between the renegotiation surplus for $\beta=\beta_{\text {max }}$ and the surplus for $\beta=1$. For high bankruptcy costs, the difference in the surpluses is negative, which implies that setting a lower coupon is better, in order to reduce the probability of reaching bankruptcy. For low

\footnotetext{
${ }^{28}$ We mention that it could be the case that in order to avoid paying a high sustainable coupon, the equity holder has incentives to ask for an even higher unsustainable coupon. This is because at these levels of the coupon, renegotiation is very likely, and the coupon is significantly reduced. To this extent, it is possible that the reduced coupon is lower than the initial coupon the equity holder was trying to avoid in the first place.

${ }^{29}$ Note that this is the present value of the increase in firm value due to renegotiation computed at the moment of debt issuance, that is at time 0 . It thus takes into account the discount rate and the probability of renegotiation. The increase in firm value evaluated at the moment of renegotiation is much higher, around $50 \%$ for our baseline case.

${ }^{30}$ Of course this is true for the given parameter values, $\tau=0.35, r=0.06$, and $C=7$. This surplus could be higher or lower, for different parameters.
} 


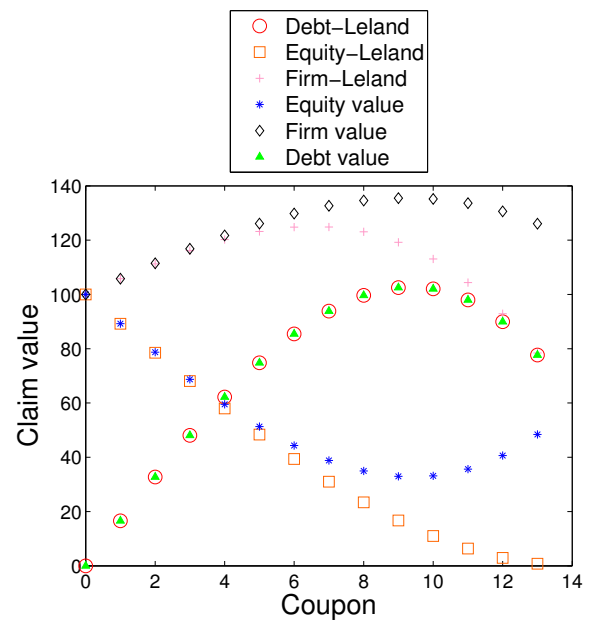

a) $\beta=1$

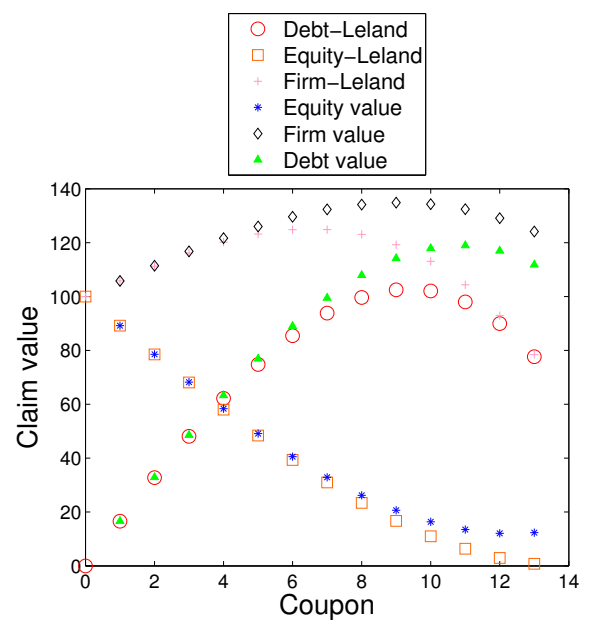

b) $\beta=\beta_{\max }$

Figure 5: Sharing of the renegotiation surplus. Panel a) overlaps Fig. 4 a) and b), that is, claim values given by Leland and claim values given by our single costless renegotiation model. In panel a) the equity holder has all bargaining power $(\beta=1)$. Panel b) presents the case $\beta=\beta_{\text {max }}$, where creditors have all bargaining power.

bankruptcy costs, the difference is positive, which means that a higher coupon is better as the firm can take advantage of the tax benefit.

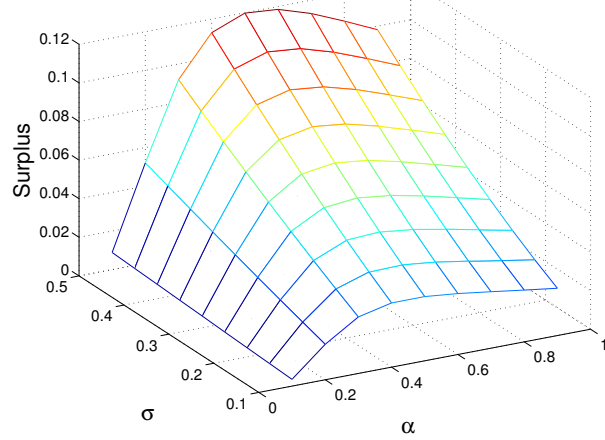

a) Surplus for $\beta=1$

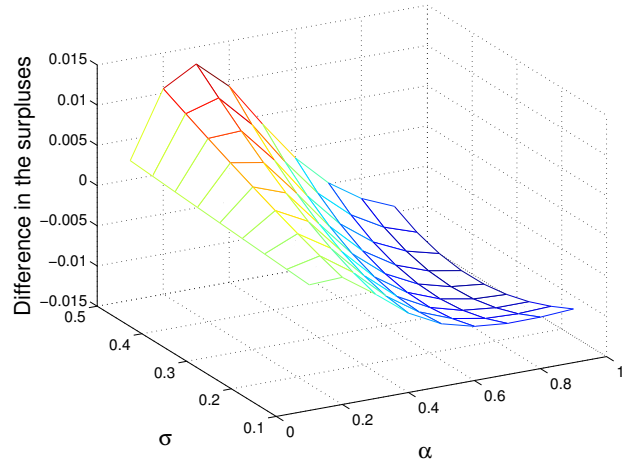

b) Surplus for $\beta=\beta_{\max }$ - surplus for $\beta=1$

Figure 6: Renegotiation surplus for one costless renegotiation. The plots are presented as a function of business and financial risk (volatility $\sigma$ and bankruptcy $\operatorname{costs} \alpha$ ). The surplus for $\beta=1$ is shown in panel a). The difference in the surpluses for $\beta=\beta_{\text {max }}$ and $\beta=1$ is shown in panel b).

\subsection{Multiple renegotiations and renegotiation costs}

We now turn to the most interesting implications of our model, namely we provide numerical examples for the case in which we allow for multiple renegotiations and renegotiation costs. We investigate the two polar cases in which the equity holder, respectively the creditors have all bargaining power.

We start by analyzing the optimal number of renegotiations and optimal capital structure in our main model, under the assumption that the party that has all bargaining power suffers the renegotiation cost. When finding the optimal number of renegotiations and the optimal initial coupon chosen by the equity holder we proceed in two steps. First, for a given initial coupon value we choose $n^{*}$ optimally as explained in Subsection 4.1. Then we choose $C^{*}$, the optimal initial coupon in order to maximize firm value (equity value plus debt proceeds). For renegotiation costs $K=1$, we find an initial optimal coupon $C^{*}=9.3$ and an optimal number of renegotiations $n^{*}=3$. 
When creditors have all bargaining power, they choose the optimal initial coupon $C^{*}$ and the optimal number of renegotiations $n^{*}$ that maximize debt value. For the baseline parameter values and renegotiation costs $K=10$, we find $n^{*}=3$ and $C^{*}=11.2$.

Comparing the two polar cases, we can say that when creditors have all bargaining power the number of renegotiations is much higher. ${ }^{31}$ At the same time, the optimal initial coupon is higher with respect to the case in which the equity holder has all bargaining power. In order to shed some light on these results we present the following table, in which we analyze the details of the renegotiation process.

Table 3: Optimal renegotiation outcomes

\begin{tabular}{ccc}
\hline Results & $\beta=1$ & $\beta=\beta_{\max }$ \\
\hline$K$ & 1 & 10 \\
$C^{*}$ & 9.3 & 11.2 \\
$n^{*}$ & 3 & 3 \\
\hline$E\left(V, C^{*}, n^{*}\right)$ & 32.73 & 11.82 \\
$D\left(V, C^{*}, n^{*}\right)$ & 102.73 & 117.84 \\
$c_{1}$ & 2.54 & 9.28 \\
$c_{2}$ & 0.69 & 7.18 \\
$c_{3}$ & 0.19 & 4.79 \\
$V_{S_{1}}$ & 66.25 & 79.78 \\
$V_{S_{2}}$ & 18.10 & 66.10 \\
$V_{S}^{3}$ & 4.95 & 51.15 \\
$V_{B}^{3}$ & 1.35 & 34.12 \\
\hline
\end{tabular}

For the parameter values mentioned above, $K=1$ when the equity holder has all bargaining power and $K=10$ when creditors have full bargaining power, we present the total value of debt and equity at time zero, the values of the reduced coupons, the renegotiation thresholds and the final liquidation threshold.

We can see that the equity holder chooses a smaller initial coupon (for $K=1$ the creditors would choose a coupon value even higher than 11.2). The first renegotiation occurs when the assets value reaches 66.25 (remember that we start with an asset value of 100 at time zero). At this threshold the coupon is reduced from 9.3 to 2.54 . This is a huge reduction, $\gamma=0.27$, which means the coupon is reduced to $27 \%$ of its initial value. The second renegotiation occurs when/if the assets value reaches 18.10. This is the threshold at which in the absence of renegotiation the equity holder would no longer be willing to pay the coupon of 2.54 and would default (Leland's default threshold). At this renegotiation stage the coupon is reduced again to $27 \%$ of its value, that is from 2.54 to 0.69 . Finally, when the assets value reaches 4.95 the coupon is reduced for the last time to 0.19 . The firm is liquidated when the assets value reaches 1.35. Of course this is an extreme situation where we assume the equity holder has full bargaining power. In reality the bargaining power will be distributed among the two parties. Nevertheless, we could say that when the equity holder has a higher bargaining power the coupon reduction is more likely to be substantial, and the number of renegotiations small, even for low costs of renegotiation.

When creditors have all bargaining power, the coupon is reduced earlier and fewer. The first renegotiation occurs when the assets value reaches 79.78 and the coupon is reduced from the initial value of 11.2 to 9.28. That is, the coupon is reduced to approximately $83 \%$ of its initial value. At the second renegotiation the coupon will be reduced further to 7.18, that is approximately $77 \%$ of its previous value. Finally, at the last renegotiation, the coupon is reduced to 4.79 , approximately $67 \%$ of the previous value. These percentages correspond to what we defined as $\phi_{i}$, where we have that $\phi_{1}=0.8285=\frac{c_{1}}{c}, \phi_{2}=0.7734=\frac{c_{2}}{c_{1}}$ and $\phi_{3}=0.6678=\frac{c_{3}}{c_{2}}$. Creditors reduce the coupon gradually, and much fewer compared to the equity holder.

\footnotetext{
${ }^{31}$ Note that we consider much higher renegotiation costs when creditors have all bargaining power, $K=10$, than when the equity holder has all bargaining power, $K=1$. For low renegotiation costs of $K=1$ creditors would renegotiate much more than just 3 times.
} 
The optimal coupon reduction, characterized by the parameters $\gamma$ and $\phi$, is presented in Table 4 for the two polar cases, for a given total number of renegotiations $n=5$. When the equity holder has all bargaining power, the coupon is reduced to $27 \%$ of its previous value at each renegotiation stage. When creditors have all bargaining power the coupon is initially reduced only to $88 \%$ of its initial value. The reduction progressively increases as they renegotiate more. At the last renegotiation stage they reduce the coupon to $67 \%$ of its previous value.

Table 4: Optimal coupon reductions, $\gamma$ and $\phi_{i}$ for $n=5$ renegotiations

\begin{tabular}{cccccc}
\hline Results & $i=1$ & $i=2$ & $i=3$ & $i=4$ & $i=5$ \\
\hline$\gamma$ & 0.27 & 0.27 & 0.27 & 0.27 & 0.27 \\
$\phi_{i}$ & 0.88 & 0.86 & 0.83 & 0.77 & 0.67 \\
\hline
\end{tabular}

We now provide the optimal number of renegotiations and optimal initial coupon for different renegotiation costs for the two polar cases of equity holder having all bargaining power $(\beta=1)$ and creditors having all bargaining power $\left(\beta=\beta_{\max }\right)$. Table 5 presents the results under the main assumption that the party that has the bargaining power suffers the cost (the first line of the table indicates who has the bargaining power, while the second one indicates who suffers the renegotiation cost).

Table 5: Optimal number of renegotiations

\begin{tabular}{lcclcc}
\hline & \multicolumn{2}{c}{$\beta=1$} & & \multicolumn{2}{c}{$\beta=\beta_{\text {max }}$} \\
\cline { 2 - 3 } \cline { 5 - 6 } Cost & \multicolumn{2}{c}{ eq holder } & & \multicolumn{2}{c}{ creditors } \\
$K$ & $C^{*}$ & $n^{*}$ & & $C^{*}$ & $n^{*}$ \\
\hline 1 & 9.3 & 3 & & 13.05 & 14 \\
5 & 8.95 & 2 & & 11.95 & 5 \\
10 & 8.5 & 1 & & 11.2 & 3 \\
20 & 7.8 & 1 & & 10.2 & 1 \\
\hline
\end{tabular}

One can observe that even for low renegotiation costs $K=1$ (that is $1 \%$ of the initial assets value), the number of renegotiations when the equity holder has all bargaining power is small (3). For higher renegotiation costs, the firm is restructured only once or twice. When creditors have all bargaining power, the number of renengotiations is much higher. For example, a cost $K=5$ (5\% of the initial assets value) leads to 5 renegotiations. Since in the real world bargaining power would be shared by the two parties we conclude that the optimal number of renegotiations would be within the values obtained for the two polar cases.

Finally, we relax our assumption regarding fixed renegotiation costs. In Table 6 we present the optimal number of renegotiations for geometrically decreasing costs. The renegotiation cost at the first renegotiation cost is equal to $K$, and the common ratio of the geometric progression is $q$. Thus, the renegotiation cost at any stage $i$ is equal to $K * q^{i-1}$. We present the optimal number of renegotiations for different common ratios varying from $q=0.9$ to $q=0.6$.

Table 6: Optimal number of renegotiations for decreasing costs

\begin{tabular}{cr|ccccc}
\hline$n^{*}$ & $K$ & $q=1$ & $q=0.9$ & $q=0.8$ & $q=0.7$ & $q=0.6$ \\
\hline$\beta=1$ & 1 & 3 & 3 & 4 & 4 & 5 \\
$\beta=\beta_{\max }$ & 20 & 1 & 2 & 2 & 4 & 12 \\
\hline
\end{tabular}

As expected, the larger the decrease in the renegotiation costs (the smaller $q$ ), the higher the optimal number of renegotiations obtained. A decrease of $40 \%$ in the renegotiation costs at each renegotiation stage would imply an 
optimal number of renegotiations of 5 when the equity holder has the bargaining power, compared to 3 for fixed costs $K=1$. When creditors have the power, the same relative decrease in costs would imply an increase in the optimal number of renegotiations from 1 for fixed costs $K=20$, to 12 for geometrically decreasing costs.

The analysis above was under the main assumption that the party that has the bargaining power suffers the renegotiation costs. We now verify whether our results are robust to assuming that the equity holder always suffers the renegotiation costs. Under the alternative assumption, the polar case of the equity holder having all bargaining power does not change. When creditors have all bargaining power and the equity holder suffers the cost we obtain very similar results for the number of renegotiations, as shown in Table $7 .{ }^{32}$

Table 7: Optimal number of renegotiations under the main and alternative assumptions

\begin{tabular}{lccccc}
\hline & \multicolumn{2}{c}{$\beta=\beta_{\max }$} & & \multicolumn{2}{c}{$\beta=\beta_{\max }$} \\
\cline { 2 - 3 } \cline { 5 - 6 } Cost & \multicolumn{2}{c}{ creditors } & \multicolumn{2}{c}{ eq holder } \\
$K$ & $C^{*}$ & $n^{*}$ & & $C^{*}$ & $n^{*}$ \\
\hline 10 & 11.2 & 3 & & 12.2 & 3 \\
15 & 10.7 & 2 & & 11.8 & 3 \\
20 & 10.2 & 1 & 11.4 & 2 \\
\hline
\end{tabular}

Regarding the coupon reduction, we consider a renegotiation cost $K=10$ for which the optimal number of renegotiations is $n^{*}=3$ and optimal initial coupon is $C^{*}=12.2$. The reduced coupons are $c_{1}=8.55, c_{2}=5.47$ and $c_{3}=2.99$. All these coupons are chosen such that the equity holder is indifferent between renegotiating or not $\left(C_{K_{i}}\right)$, thus the creditors take all the renegotiation surplus. Consequently, the equity value is equal to Leland's equity. This corresponds to the coupons being reduced to $\phi_{1}=0.70, \phi_{2}=0.64$, and $\phi_{3}=0.55$ respectively, of the previous coupon value. These values are in between those that we obtained for $\gamma$ and $\phi$ under the main assumption. As before, creditors reduce the coupon gradually, starting with a smaller reduction in the first stage, and larger reduction in the final stage. Compared to the main assumption under which creditors suffered the renegotiation costs, the coupon reduction is larger. This makes sense, as larger coupon reductions would allow the equity holder to pay the renegotiation costs.

Since we obtain similar results under both assumptions, especially regarding the number of renegotiations (the main novelty of our paper), we conclude that our results are not driven by the simplifying assumption made, and that our model is quite robust.

Comparing with the empirical evidence, for these values of renegotiation costs, our results are in line with empirical evidence showing that the number of firms that undertake a second debt reorganization after a first debt restructuring is small. LoPucki and William C. (1993), as well as Hotchkiss (1995) find that only 32\%, Gilson (1997) 33\% and Alderson and Betker (1999) 24\% of firms undertake a second reorganization. These studies refer to formal Chapter 11 reorganizations. One can expect these numbers to be slightly higher for private workouts, given that the cost of a private workout is smaller than the cost of a Chapter 11 reorganization. Indeed, Roberts (2010) finds an average of 4 private workouts for the typical loan.

Although it is hard to estimate the costs of private renegotiations or of formal bankruptcy, the few empirical studies available suggest that our values are realistic. Gilson et al. (1990) review the existing evidence and claim that direct bankruptcy costs vary from 5.3 percent of the firm's market value at the time of bankruptcy on average, to 7.5 percent of total liquidation proceeds, and 2.9 percent of book value prior to filing. These are just direct costs, to which one should add the value of indirect costs, much harder to estimate. For direct costs of private debt-restructuring they find an average of 0.65 percent of the book value of assets and 2.16 percent of the face value of bonds restructured (based on a sample of 18 exchanges). Their maximum values are 3.4 percent and 6.84 percent respectively.

\footnotetext{
${ }^{32}$ For higher renegotiation costs we obtain very similar number of renegotiations under the two assumptions. For smaller renegotiations costs $(K=5$ or $K=1)$, unfortunately the results are intractable.
} 


\section{Empirical implications}

Our model has a number of testable implications for debt renegotiation, several of which are novel with respect to the existent literature. In this section, we briefly discuss these implications that concern (1) the renegotiation threshold, (2) the coupon reduction, (3) the number of renegotiations, and (4) the optimal capital structure.

\subsection{Renegotiation threshold}

First of all, our model shows that renegotiation only occurs when the firm is in financial distress. This differs from previous contributions which argue that renegotiation can happen even when the firm is financially healthy, and that the equity holder can extract concessions from creditors, if bankruptcy costs are high (see Mella-Barral and Perraudin, 1997). Our results are supported by empirical evidence from Daniels et al. (2013). In a sample of firms that have issued corporate bonds with clawback provisions, they find that firms which renegotiate their debt tend to have a higher leverage ratio, a lower return on equity, and are more likely to be a noninvestment grade firm. This suggests that firms which renegotiate their debt are more likely to be in financial distress.

Secondly, our model shows that the renegotiation timing does not depend on the bargaining power of the claimants. Previous contributions argue that renegotiation takes place earlier when the equity holder has the power rather than the creditors. In our model, renegotiation takes place when the firm is financially distressed and the equity holder refuses to continue satisfying the financial obligations in the absence of renegotiation. This result is independent of the bargaining power distribution.

\subsection{Coupon reduction}

A second set of implications of our model concerns the coupon reduction. We show that bargaining power plays a critical role in determining the size of the concessions obtained in renegotiation. Our model predicts that small firms, which have a concentrated group of creditors who closely monitor them (in which creditors have a higher relative bargaining power), are likely to obtain smaller concessions compared to large firms with a high number of institutional investors, or in which a high percentage of the equity is held by institutional investors (in which the equity holder has a higher relative bargaining power).

The dynamics of renegotiation differ as well depending on the bargaining power of the claimants. Firms where creditors have a higher relative bargaining power obtain relatively larger concessions in the last renegotiation rounds. By contrast, large firms with deep pockets, where the equity holder is more likely to have a high bargaining power, obtain relatively similar concessions at all renegotiation stages.

\subsection{Number of renegotiations}

Another empirical prediction of our model is that firms where creditors have higher bargaining power experience a higher number of renegotiations prior to liquidation. To our knowledge, this is a novel prediction, as we are the first to investigate the optimal number of renegotiations.

Thus, our model predicts a higher number of renegotiations on markets in which lenders competition is small, for smaller firms affected by informational asymmetry, and for firms without institutional investors. Our prediction is in line with empirical evidence presented by Roberts (2010). He finds that both firm size and the Z-score have economically significant negative effects on the number of renegotiations. Thus smaller riskier firms with lower Z-scores, more opaque and with higher informational asymmetry (in which creditors are likely to have a higher bargaining power) tend to experience more renegotiations.

A further implication of our model is that the number of renegotiations decreases with renegotiation costs, as expected. Since renegotiation costs are higher for firms which have more public rather than private debt (because of the free-rider and coordination problems), for firms with a complex capital structure and international creditors, we expect this kind of firms to have a lower number of renegotiations. 


\subsection{Optimal capital structure}

Our results show that leverage depends on bargaining power. According to our model, firms in which the creditors have higher bargaining power have higher leverage ratios. This result is consistent with Hege and Mella-Barral (2000)'s prediction. Indeed, they show that for reasonable parameter values, leverage ratios are one quarter lower when the equity holder has the bargaining power than when creditors have the power.

Finally, our simulations suggest that there exists a positive relationship between the optimal initial coupon and the number of renegotiations. The higher the initial coupon, the higher the number of renegotiations. This prediction is in line with empirical evidence presented by Roberts (2010) showing that the amount and interest rate of a loan are strongly positively correlated with the number of renegotiation rounds.

\section{Conclusions}

This study presents a model of debt renegotiation, in the framework of a structural model that accounts for taxes, bankruptcy costs and renegotiation costs. Following Mella-Barral (1999) and Lambrecht (2001), we propose renegotiation in the form of permanent coupon reductions. Our main contribution is that we incorporate fixed renegotiation costs, which results in a finite number of "lumpy" coupon reductions (as opposed to the infinitesimal infinite coupon reductions in Mella-Barral, 1999). This allows us on the one hand to analyze the optimal number of renegotiations. To our knowledge, our paper is the first to investigate the optimal number of renegotiations and to provide a range for the coupon reduction. We show that the firm will have a small finite number of renegotiations, which is in line with empirical evidence. Moreover, we derive a series of novel testable implications regarding the renegotiation threshold, the coupon reduction, the number of renegotiations and optimal capital structure.

On the other hand, we derive a series of novel testable implications regarding the renegotiation threshold, the coupon reductions, the number of renegotiations and the optimal capital structure, that we summarize below. First, our model shows that the renegotiation timing does not depend on the bargaining power of the claimants. Renegotiation takes place when the firm is financially distressed and the equity holder refuses to continue satisfying the financial obligations in the absence of renegotiation.

Another implication of our model is that bargaining power plays a critical role in determining the size of the concessions obtained in renegotiation and the optimal number of renegotiations. Firms where creditors have higher bargaining power (smaller financially constrained firms that have a close relationship with their creditors) experience a higher number of renegotiations prior to liquidation. At the same time, they obtain smaller concessions compared to firms where the equity holder has a higher relative bargaining power. The dynamics of renegotiation also differ depending on the bargaining power of the claimants. Firms where creditors have a higher relative bargaining power obtain relatively larger concessions in the last renegotiation rounds, while large firms with deep pockets, where the equity holder is more likely to have a high bargaining power, obtain relatively similar concessions at all renegotiation stages. Finally, the model predicts a positive relationship between the optimal initial coupon and the number of renegotiations, in line with empirical evidence.

We now suggest different avenues for future research. In our model, we have analyzed debt renegotiation abstracting from any debt covenants (default and renegotiation thresholds are endogenously chosen). There exists empirical evidence which shows that many times firms do not succeed in renegotiating their debt and many forced liquidations are observed. ${ }^{33}$ Some of these liquidations could be triggered by various bond covenants. Our framework could be extended to account for cash flow-based covenants, which imply that when the firm does not generate enough cash flow to meet the interest payment, the creditors will liquidate the firm. ${ }^{34}$ As Fan and Sundaresan (2000) argue, if the cash flow covenant becomes a binding constraint before the renegotiation threshold is reached, then forced liquidations can occur. Otherwise, if renegotiation occurs before the covenant becomes binding, forced liquidations will be avoided. Given the significant reduction in the coupon payment, the renegotiation process proposed here could be a solution for any liquidity problems the firm might have that could impede it from satisfying such a covenant. ${ }^{35}$

\footnotetext{
${ }^{33}$ Gilson et al. (1990) report more than $50 \%$ of the firms did not succeed in private debt restructuring of their debt.

${ }^{34}$ Since there are no cash flows in our model, we would need to include a cash payout ratio in the diffusion process of the assets value of the firm, which would affect the formulas we obtain for $X$.

${ }^{35} \mathrm{Fan}$ and Sundaresan (2000) analyze the impact of a cash flow covenant in an asset value-based model of temporary debt renegotiation (in which the state variable is the assets value and there exists a cash payout ratio).
} 
We have presented an asset value-based valuation model, with the state variable being the value of the firm and we have found that the renegotiation threshold reduces to the liquidation threshold. An interesting question would be to analyze the use of a cash flow-based model compared to a value-based model. Another potential question is how the renegotiation process changes with heterogeneous debt (bank loan versus public debt, senior versus subordinated debt). This agenda is left for future research.

\section{Acknowledgements}

We are grateful for the comments of an anonymous referee and the editor. We thank Carole Bernard, Regis Blazy, Max Bruche, Ricardo Correia, Sébastien Galanti, Itay Goldstein, Dirk Hackbarth, Stefan Hirth, Ambrus Kecskés, Elisa Luciano, and Josep Antonio Tribo, as well as conference participants at the FMA European Conference, Luxembourg 2013, Swiss Society for Financial Market Research, Zurich, Switzerland 2013, French Finance Association, Strasbourg, France 2012, GdRE Symposium on Money, Banking and Finance, Nantes, France 2012, Spanish Finance Association, Oviedo, Spain 2012, and seminar participants at Aarhus University, Denmark 2012, University of Rennes 1, France 2012 and University of Orleans, France 2012 for valuable comments and suggestions. We gratefully acknowledge financial support from CREM and IGR.

\section{Appendix A.}

Proof of Proposition 1. Debt and equity prices are made of building blocks that can be priced by simple but lengthy application of the Law of iterated expectations. First of all, the present value of one euro received the first time a threshold $K$ is hit is well known to be $\left(\frac{V}{K}\right)^{-X}$. As the default threshold fully characterizes the liquidated value of the firm's assets, the present value of bankruptcy costs amounts to $(1-\alpha) V_{B}^{\prime}\left(\frac{V}{V_{B}^{\prime}}\right)^{-X}$. Next, a coupon to be paid or to be received between time zero and the first hitting time of a threshold $\mathrm{K}$ is given by:

$$
\begin{aligned}
E\left[\int_{0}^{\tau_{K}} c \exp (-r s) \mathrm{d} s\right] & =E\left[\int_{0}^{\infty} c \exp (-r s) \mathrm{d} s-\int_{\tau_{K}}^{\infty} c \exp (-r s) \mathrm{d} s\right] \\
& =\frac{c}{r}-c E\left[\int_{0}^{\infty} \exp \left(-r\left(s+\tau_{K}\right)\right) \mathrm{d} s\right] \\
& =\frac{c}{r}\left\{1-E\left[\exp \left(-r \tau_{K}\right)\right]\right\} \\
& =\frac{c}{r}\left(1-\left(\frac{V}{K}\right)^{-X}\right) .
\end{aligned}
$$

So we can deduce from this that receiving $c$ until $V_{S}$ is reached is worth $\frac{c}{r}\left(1-\left(\frac{V}{V_{S}}\right)^{-X}\right)$. Finally, receiving a coupon flow $c^{\prime}$ between the first hitting time of $V_{S}$ and $V_{B}^{\prime}$ is worth:

$$
\begin{aligned}
E\left[\int_{\tau_{V_{S}}}^{\tau_{V_{B}^{\prime}}} c^{\prime} \exp (-r s) \mathrm{d} s\right] & =E\left[\int_{0}^{\tau_{V_{B}^{\prime}}-\tau_{V_{S}}} c^{\prime} \exp (-r s) \mathrm{d} s \exp \left(-r \tau_{V_{S}}\right)\right] \\
& =\frac{c^{\prime}}{r} E\left[\left(1-\exp \left(-r\left(\tau_{V_{B}^{\prime}}-\tau_{V_{S}}\right)\right)\right) \exp \left(-r \tau_{V_{S}}\right)\right] \\
& =\frac{c^{\prime}}{r} E\left[\left(1-\exp \left(-r\left(\tau_{V_{B}^{\prime}}-\tau_{V_{S}}\right)\right)\right)\right] E\left[\exp \left(-r \tau_{V_{S}}\right)\right] \\
& =\frac{c^{\prime}}{r}\left(1-\left(\frac{V_{S}}{V_{B}^{\prime}}\right)^{-X}\right)\left(\frac{V}{V_{S}}\right)^{-X} .
\end{aligned}
$$

Summing these three terms, we obtain the debt value given in Eq. (4). The equity value is deduced in a similar way.

Proof of Proposition 2. The equity and debt value for the case of multiple costly renegotiations are derived similarly to the case of one costless renegotiation. The mathematical techniques are provided above. 
Proof of Lemmas 1 and 2. In order to prove that equity is decreasing in the renegotiation thresholds we will use the backward recursive technique and proof by induction.

We start by showing that equity is decreasing in the renegotiation threshold for one costless renegotiation. We will then show that as a consequence of this result Lemma 2 holds for one costless renegotiation. We then prove these results for a single costly renegotiation. This first step represents the base case of our proof by induction. In a second step, the inductive step, we will show that if equity is decreasing in the renegotiation thresholds for $n-1$ costly renegotiations, then it is also decreasing in the renegotiation thresholds for $n$ renegotiations. We will then proceed similarly for the coupon reduction given by Lemma 2 . This will complete our proof of both lemmas.

One costless renegotiation. We know from Eq. (5) that:

$$
E\left(V, c, V_{S}, c^{\prime}, V_{B}^{\prime}\right)=V-(1-\tau) \frac{c}{r}\left(1-\left(\frac{V}{V_{S}}\right)^{-X}\right)-(1-\tau) \frac{c^{\prime}}{r}\left(1-\left(\frac{V_{S}}{V_{B}^{\prime}}\right)^{-X}\right)\left(\frac{V}{V_{S}}\right)^{-X}-V_{B}^{\prime}\left(\frac{V}{V_{B}^{\prime}}\right)^{-X},
$$

where $V_{B}^{\prime}=\frac{(1-\tau) c^{\prime}}{r} \frac{X}{1+X}$ and $c^{\prime}$ is a function of $V_{S}$.

Differentiating with respect to $V_{S}$ we obtain:

$$
\frac{d E}{d V_{S}}=\underbrace{\frac{\partial E}{\partial V_{S}}}_{\text {direct effect }}+\underbrace{\left(\frac{\partial E}{\partial c^{\prime}}+\frac{\partial E}{\partial V_{B}^{\prime}} \frac{\partial V_{B}^{\prime}}{\partial c^{\prime}}\right) \frac{\partial c^{\prime}}{\partial V_{S}}}_{\text {indirect effect }} .
$$

We have that:

$$
\begin{gathered}
\frac{\partial E}{\partial V_{S}}=\frac{(1-\tau)}{r}\left(\frac{V}{V_{S}}\right)^{-X} \frac{X}{V_{S}}\left(c-c^{\prime}\right), \\
\frac{\partial E}{\partial c^{\prime}}=-\frac{(1-\tau)}{r}\left(\frac{V}{V_{S}}\right)^{-X}\left(1-\left(\frac{V_{S}}{V_{B}^{\prime}}\right)^{-X}\right),
\end{gathered}
$$

and

$$
\frac{\partial E}{\partial V_{B}^{\prime}}=0
$$

since $V_{B}^{\prime}$ is optimally chosen to maximize equity value.

Replacing the three terms in the equation above we obtain:

$$
\begin{aligned}
\frac{d E}{d V_{S}} & =\underbrace{\frac{\partial E}{\partial V_{S}}}_{\text {direct effect }>0}+\underbrace{\frac{\partial E}{\partial c^{\prime}} \frac{\partial c^{\prime}}{\partial V_{S}}}_{\text {indirect } \text { effect }<0} \\
& =\frac{(1-\tau)}{r}\left(\frac{V}{V_{S}}\right)^{-X}\left\{\frac{X}{V_{S}}\left(c-c^{\prime}\right)-\left[1-\left(\frac{V_{S}}{V_{B}^{\prime}}\right)^{-X}\right] \frac{\partial c^{\prime}}{\partial V_{S}}\right\} .
\end{aligned}
$$

Now we need to determine the derivative of $c^{\prime}$ with respect to $V_{S}$. For this we apply the implicit function theorem in Eq. (10), according to which the derivative of $c^{\prime}$ with respect to $V_{S}$ is:

$$
\frac{\partial c^{\prime}}{\partial V_{S}}=-\frac{\partial H / \partial V_{S}}{\partial H / \partial c^{\prime}}
$$

where

$$
H\left(c^{\prime}, V_{S}\right)=c^{\prime} / r+\left[(1-\alpha) V_{B}^{\prime}-c^{\prime} / r\right]\left(V_{S} / V_{B}^{\prime}\right)^{-X}-c / r-\left[(1-\alpha) V_{B}-c / r\right]\left(V_{S} / V_{B}\right)^{-X} .
$$

We compute the partial derivatives:

$$
\begin{aligned}
\frac{\partial H}{\partial V_{S}} & =\left[(1-\alpha) V_{B}-c / r\right] X V_{S}^{-X-1} V_{B}^{X}-\left[(1-\alpha) V_{B}^{\prime}-c^{\prime} / r\right] X V_{S}^{-X-1} V_{B}^{\prime X} \\
& =\frac{X V_{S}^{-1}}{r}\left(c^{\prime}-c\right),
\end{aligned}
$$


where we have used Eq. (10) in the second equality.

$$
\begin{aligned}
\frac{\partial H}{\partial c^{\prime}} & =\frac{1}{r}-\frac{(X+1) V_{S}^{-X} V_{B}^{\prime X}}{r}+(1-\alpha)(X+1) V_{S}^{-X} V_{B}^{\prime X} \frac{(1-\tau) X}{r(X+1)} \\
& =\frac{1}{r}\left\{1-V_{S}^{-X} V_{B}^{\prime X}[X+1-(1-\alpha)(1-\tau) X]\right\} .
\end{aligned}
$$

Let $R=X+1-(1-\alpha)(1-\tau) X$, then replacing the last two results in Eq. (A.2), we obtain:

$$
\frac{\partial c^{\prime}}{\partial V_{S}}=\frac{X V_{S}^{-1}\left(c-c^{\prime}\right)}{1-V_{S}^{-X} V_{B}^{\prime X} R}
$$

Coming back to the derivative of equity with respect to $V_{S}$ in Eq. (A.1), we obtain:

$$
\begin{aligned}
\frac{d E}{d V_{S}} & =\frac{(1-\tau)}{r} V^{-X}\left[V_{S}^{X-1} X\left(c-c^{\prime}\right)+\frac{X V_{S}^{-1}\left(c-c^{\prime}\right)\left(V_{B}^{\prime X}-V_{S}^{X}\right)}{1-V_{S}^{-X} V_{B}^{\prime X} R}\right] \\
& =\frac{(1-\tau)}{r} V^{-X} V_{S}^{-1} X\left[V_{S}^{X}\left(c-c^{\prime}\right)+\frac{\left(c-c^{\prime}\right)\left(V_{B}^{\prime X}-V_{S}^{X}\right)}{1-V_{S}^{-X} V_{B}^{\prime X} R}\right] \\
& =\frac{(1-\tau)}{r} V^{-X} V_{S}^{-1} X\left[\frac{V_{S}^{X}\left(c-c^{\prime}\right)-V_{B}^{\prime X}\left(c-c^{\prime}\right) R+\left(c-c^{\prime}\right)\left(V_{B}^{\prime X}-V_{S}^{X}\right)}{1-V_{S}^{-X} V_{B}^{\prime X} R}\right] \\
& =\left[\frac{(1-\tau)}{r} V^{-X} V_{S}^{-1} X\right] \frac{V_{B}^{\prime X}\left(c-c^{\prime}\right)(1-R)}{1-V_{S}^{-X} V_{B}^{\prime X} R} .
\end{aligned}
$$

Analyzing the sign of this result, we observe that the first factor in between square brackets is positive as the new coupon is inferior to the initial one. The denominator of the second fraction represents the derivative of $H$ with respect to $c^{\prime}$. As the right hand side of Eq. (10) does not depend on $c^{\prime}$, this is also the derivative of $d\left(V_{S}, c^{\prime}, V_{B}\left(c^{\prime}\right)\right)$ with respect to $c^{\prime}$. Furthermore, as we consider coupon values strictly below the coupon that maximizes debt value at $V_{S}, C_{\max }\left(V_{S}\right)$, we know from Leland (1994) that this derivative is positive in this region, so that the denominator of the fraction is positive. Finally, the numerator of the fraction is negative since $1-R=-X(1-(1-\alpha)(1-\tau))<0$. Therefore we obtain that the derivative of equity with respect to $V_{S}$ is negative: equity is decreasing in $V_{S}$.

To show that $c^{\prime} / c=\gamma$, where $\gamma$ is defined by Eq. (11), we rewrite the left hand side of Eq. (10) as follows: $\frac{c^{\prime}}{r}\left(1-\left(\frac{V_{B}}{V_{B}^{\prime}}\right)^{-X}\right)+(1-\alpha) V_{B}^{\prime}\left(\frac{V_{B}}{V_{B}^{\prime}}\right)^{-X}=(1-\alpha) V_{B}$

Plugging $V_{B}=A c$ and $V_{B}^{\prime}=A c^{\prime}$ with $A=\frac{(1-\tau) X}{r(X+1)}$ in this equation leads to

$$
\frac{1}{r(1-\alpha) A} \frac{c^{\prime}}{c}\left(1-\left(\frac{c}{c^{\prime}}\right)^{-X}\right)+\frac{c^{\prime}}{c}\left(\frac{c}{c^{\prime}}\right)^{-X}=1 .
$$

Replacing $c^{\prime} / c$ by $\gamma$, we get:

$$
\frac{\gamma\left(1-\gamma^{X}\right)}{r(1-\alpha) A}+\gamma^{X+1}=1
$$

Replacing for $A$ we obtain Eq. (11), which proves Lemma 2 for the case of one costless renegotiation.

One costly renegotiation. If renegotiation is costly, then the equity value will decrease by an amount $K$ at renegotiation with respect to the equity value with costless renegotiation:

$$
E_{\text {cost }}\left(V, c, V_{S}, c^{\prime}, V_{B}^{\prime}\right)=E\left(V, c, V_{S}, c^{\prime}, V_{B}^{\prime}\right)-K\left(\frac{V}{V_{S}}\right)^{-X} .
$$

Deriving with respect to $V_{S}$, we obtain:

$$
\frac{d E_{\text {cost }}}{d V_{S}}=\frac{d E}{d V_{S}}-K X V^{-X} V_{S}^{X-1}<\frac{d E}{d V_{S}}
$$


But we have just proven that $\frac{d E}{d V_{S}}<0$, therefore we have $\frac{d E_{\text {cost }}}{d V_{S}}<0$. For one single costly renegotiation, it is optimal for the equity holder to renegotiate as late as possible since equity is decreasing in $V_{S}$. Since introducing renegotiation costs does not affect the value of the reduced coupon, the coupon reduction will be the same as in the costless renegotiation case. This implies Lemma 2 also holds for one costly renegotiation.

Multiple renegotiations. We now continue with the inductive step of the proof for multiple costless renegotiations. Adding renegotiation costs to multiple renegotiations will only reinforce our results. We assume that Lemma 1 and Lemma 2 hold for $n-1$ renegotiations. We then prove that they also hold for $n$ renegotiations.

Since we are using the backward recursive technique, assuming the two lemmas hold for $n-1$ renegotiations implies that for all $i \in\{2, \ldots, n\}$ equity is decreasing in the renegotiation thresholds, thus $V_{S_{i}}=V_{B}\left(c_{i-1}\right), \frac{c_{i}}{c_{i-1}}=\gamma$, where $\gamma$ is given by Eq. (11). In order to show that they also hold for $n$ renegotiations, we need to prove that equity at time zero is a decreasing function of $V_{S_{1}}$, thus $V_{S_{1}}=V_{B}(c)$ and $\frac{c_{1}}{c}=\gamma$.

Since we know by assumption that for all $i \in\{2, \ldots, n\} V_{S_{i}}=V_{B}\left(c_{i-1}\right)$ and $\frac{c_{i}}{c_{i-1}}=\gamma$, equity value at time zero can be expressed as a function of only two variables $V_{S_{1}}$ and $c_{1}$.

As before, differentiating equity with respect to $V_{S_{1}}$ we obtain:

$$
\frac{d E}{d V_{S_{1}}}=\underbrace{\frac{\partial E}{\partial V_{S_{1}}}}_{\text {direct } \text { effect }}+\underbrace{\frac{\partial E}{\partial c_{1}} \frac{\partial c_{1}}{\partial V_{S_{1}}}}_{\text {indirect } \text { effect }} .
$$

We have that:

$$
\begin{gathered}
\frac{\partial E}{\partial V_{S_{1}}}=\frac{(1-\tau)}{r}\left(\frac{V}{V_{S_{1}}}\right)^{-X} \frac{X}{V_{S_{1}}}\left(c-c_{1}\right), \\
\frac{\partial E}{\partial c_{1}}=\frac{(1-\tau)}{r} V^{-X}\left[V_{B_{1}}{ }^{X}\left[X+1-(X+1)\left(1-\gamma^{X}\right)\left(\gamma+\gamma^{2+X}+\ldots+\gamma^{n-1+X(n-2)}\right)-X \gamma^{(X+1)(n-1)}\right]-V_{S_{1}}{ }^{X}\right] .
\end{gathered}
$$

Now we need to determine the derivative of $c_{1}$ with respect to $V_{S_{1}}$. We know that for $i=1$ Eq. (10) implicitly defines $c_{1}$ as a function of $V_{S_{1}}$ :

$$
D\left(V_{S_{1}}, c_{1}, n-1\right)=d\left(V_{S_{1}}, c, V_{B}(c)\right) \text {. }
$$

Replacing for the value of debt with multiple (costless) renegotiations and one (costless) renegotiation respectively, we obtain:

$$
\begin{aligned}
& \frac{c_{1}}{r}\left(1-\left(\frac{V_{S_{1}}}{V_{S_{2}}}\right)^{-X}\right)+\sum_{i=2}^{n-1} \frac{c_{i}}{r}\left(1-\left(\frac{V_{S_{i}}}{V_{S_{i+1}}}\right)^{-X}\right)\left(\frac{V_{S_{1}}}{V_{S_{i}}}\right)^{-X} \\
& +\frac{c_{n}}{r}\left(1-\left(\frac{V_{S_{n}}}{V_{B_{n}}}\right)^{-X}\right)\left(\frac{V_{S_{1}}}{V_{S_{n}}}\right)^{-X}+(1-\alpha) V_{B_{n}}\left(\frac{V_{S_{1}}}{V_{B_{n}}}\right)^{-X} \\
& =\frac{c}{r}\left(1-\left(\frac{V_{S_{1}}}{V_{B}}\right)^{-X}\right)+(1-\alpha) V_{B}\left(\frac{V_{S_{1}}}{V_{B}}\right)^{-X},
\end{aligned}
$$

which is an equation in $c_{1}$ and $V_{S_{1}}$ since $V_{S_{i}}=V_{B}\left(c_{i-1}\right)$ and $\frac{c_{i}}{c_{i-1}}=\gamma$, for all $i \in\{2, \ldots, n\}$.

Applying again the implicit function theorem we obtain the derivative of $c_{1}$ with respect to $V_{S_{1}}$ :

$$
\frac{\partial c_{1}}{\partial V_{S_{1}}}=-\partial H_{n} / \partial V_{S_{1}} \partial H_{n} / \partial c_{1},
$$

where

$$
\begin{aligned}
H_{n}\left(c_{1}, V_{S_{1}}\right) & =\frac{c_{1}}{r}\left(1-\left(\frac{V_{S_{1}}}{A c_{1}}\right)^{-X}\right)+\frac{c_{1} \gamma}{r}\left(1-\gamma^{X}\right)\left(\frac{V_{S_{1}}}{A c_{1}}\right)^{-X}+\frac{c_{1} \gamma^{2}}{r}\left(1-\gamma^{X}\right)\left(\frac{V_{S_{1}}}{A c_{1} \gamma}\right)^{-X} \\
& +\ldots+\frac{c_{1} \gamma^{n-1}}{r}\left(1-\gamma^{X}\right)\left(\frac{V_{S_{1}}}{A c_{1} \gamma^{n-2}}\right)^{-X}+(1-\alpha) A c_{1} \gamma^{n-1}\left(\frac{V_{S_{1}}}{A c_{1} \gamma^{n-1}}\right)^{-X} \\
& -\frac{c}{r}\left(1-\left(\frac{V_{S_{1}}}{V_{B}}\right)^{-X}\right)-(1-\alpha) V_{B}\left(V_{S_{1}} / V_{B}\right)^{-X} .
\end{aligned}
$$


Proceeding as for one single renegotiation, we obtain that:

$$
\begin{gathered}
\frac{\partial H_{n}}{\partial V_{S_{1}}}=\frac{X V_{S_{1}}^{-1}}{r}\left(c_{1}-c\right) \\
\frac{\partial H_{n}}{\partial c_{1}}=\frac{1}{r}\left[1-\left(\frac{V_{S_{1}}}{V_{B_{1}}}\right)^{-X}\left[X+1-\left(1-\gamma^{X}\right)(X+1)\left(\gamma+\gamma^{2+X}+\ldots+\gamma^{n-1+X(n-2)}\right)-(1-\alpha)(1-\tau) X \gamma^{(n-1)(X+1)}\right]\right] .
\end{gathered}
$$

For simplicity, let us use the following notation:

$$
\begin{gathered}
R_{n}=X+1-(X+1)\left(1-\gamma^{X}\right)\left(\gamma+\gamma^{2+X}+\ldots+\gamma^{n-1+X(n-2)}\right)-(1-\alpha)(1-\tau) X \gamma^{(n-1)(X+1)} \\
Q_{n}=X+1-(X+1)\left(1-\gamma^{X}\right)\left(\gamma+\gamma^{2+X}+\ldots+\gamma^{n-1+X(n-2)}\right)-X \gamma^{(n-1)(X+1)} .
\end{gathered}
$$

Then we can express the derivative of $E$ with respect to $c_{1}$ and that of $c_{1}$ with respect to $V_{S_{1}}$ as follows:

$$
\begin{gathered}
\frac{\partial E}{\partial c_{1}}=\frac{(1-\tau)}{r} V^{-X}\left[V_{B_{1}}{ }^{X} Q_{n}-V_{S_{1}}{ }^{X}\right], \\
\frac{\partial c_{1}}{\partial V_{S_{1}}}=\frac{X V_{S_{1}}^{-1}\left(c_{1}-c\right)}{1-\left(\frac{V_{S_{1}}}{V_{B_{1}}}\right)^{-X} R_{n}} .
\end{gathered}
$$

Finally, the derivative of equity with respect to the renegotiation threshold becomes:

$$
\begin{aligned}
\frac{d E}{d V_{S_{1}}}= & \frac{(1-\tau)}{r} V^{-X} V_{S_{1}}{ }^{-1} X\left[V_{S_{1}}{ }^{X}\left(c-c_{1}\right)+\left[V_{B_{1}}{ }^{X} Q_{n}-V_{S_{1}}{ }^{X}\right] \frac{c-c_{1}}{1-\left(\frac{V_{S_{1}}}{V_{B_{1}}}\right)^{-X} R_{n}}\right] \\
& =\frac{(1-\tau)}{r} V^{-X} V_{S_{1}}{ }^{-1} X\left[\frac{V_{S_{1}}{ }^{X}\left(c-c_{1}\right)-V_{B_{1}}{ }^{X}\left(c-c_{1}\right) R_{n}+\left(c-c_{1}\right)\left[V_{B_{1}}{ }^{X} Q_{n}-V_{S_{1}}{ }^{X}\right]}{1-\left(\frac{V_{S_{1}}}{V_{B_{1}}}\right)^{-X} R_{n}}\right] \\
& =\frac{(1-\tau)}{r} V^{-X} V_{S_{1}}{ }^{-1} X \frac{\left(c-c_{1}\right) V_{B_{1}}{ }^{X}\left(Q_{n}-R_{n}\right)}{1-\left(\frac{V_{S_{1}}}{V_{B_{1}}}\right)^{-X} R_{n}} .
\end{aligned}
$$

The denominator of the fraction represents the derivative of debt value with respect to the reduced coupon. Since debt is a hump-shaped function of the reduced coupon and the reduced coupon is below the coupon that maximizes debt value, the denominator will be positive. The numerator of the fraction is however negative since $Q_{n}<R_{n}$. Therefore equity is decreasing in the renegotiation threshold. It is optimal to choose $V_{S_{1}}=V_{B}$. Adding renegotiation costs would further decrease the derivative of equity with respect to the renegotiation threshold (as we have seen in the case of one renegotiation). Lemma 1 thus holds in general for multiple costly renegotiations.

We end by showing that Lemma 2 also holds for multiple renegotiations. For this we need to show that $c_{1} / c=\gamma$, where $\gamma$ is given by Eq. (11).

As we have seen above, $c_{1}$ satisfies Eq. (A.3). We have also shown that $V_{S_{1}}=V_{B}=A c$ and we know that for all $i \in\{2, \ldots, n\}$ we have $V_{S_{i}}=V_{B}\left(c_{i-1}\right)$ and $\frac{c_{i}}{c_{i-1}}=\gamma$. Replacing this in Eq. (A.3), we obtain:

$$
\frac{c_{1}}{c}\left(1-\left(\frac{c_{1}}{c}\right)^{X}\right)+\left(\frac{c_{1}}{c}\right)^{X+1}\left(1-\gamma^{X}\right)\left(\gamma+\gamma^{2+X}+\ldots+\gamma^{n-1+X(n-2)}\right)+(1-\alpha) A r\left(\frac{c_{1}}{c}\right)^{X+1} \gamma^{(n-1)(X+1)}=(1-\alpha) A r
$$

Let $c_{1} / c=\gamma$. We need to show that $\gamma$ satisfies Eq. (11). Replacing $c_{1} / c$ by $\gamma$ in the previous equation we obtain:

$$
\gamma\left(1-\gamma^{X}\right)+\gamma^{X+1}\left[\left(1-\gamma^{X}\right)\left(\gamma+\gamma^{2+X}+\ldots+\gamma^{n-1+X(n-2)}\right)+(1-\alpha) A r \gamma^{n(X+1)}\right]=(1-\alpha) A r
$$


In order to show that $\gamma$ satisfies Eq. (11) we will use the fact that $c_{2} / c_{1}=\gamma$ and that $c_{2}$ is given by the following equation:

$$
D\left(V_{S_{2}}, c_{2}, n-2\right)=d\left(V_{S_{2}}, c_{1}, V_{B_{1}}\right) .
$$

Proceeding as above one can show that the previous equation is equivalent to:

$$
\gamma\left(1-\gamma^{X}\right)+\gamma^{X+1}\left(1-\gamma^{X}\right)\left(\gamma+\gamma^{2+X}+\ldots+\gamma^{n-2+X(n-3)}\right)+(1-\alpha) A r \gamma^{X+1} \gamma^{(n-1)(X+1)}=(1-\alpha) A r .
$$

Note that the term in between square brackets from Eq. (A.4) is equal to the left hand side of Eq. (A.5), thus we can replace it by $\operatorname{Ar}(1-\alpha)$. Eq. (A.4) becomes:

$$
\gamma\left(1-\gamma^{X}\right)+\gamma^{X+1}(1-\alpha) A r=(1-\alpha) A r
$$

Dividing by $\operatorname{Ar}(1-\alpha)$ we obtain Eq. (11). This concludes our proof of Lemma 2 for multiple costless renegotiations. Since the reduced coupons do not depend on the renegotiation costs, this lemma will also hold for multiple costly renegotiations.

Proof of Lemmas 3 AND 4. As in the case of equity, we will use again the backward recursive technique and proof by induction.

We first show that debt is decreasing in the renegotiation threshold for one costless renegotiation. We will then show that as a consequence of this result Lemma 4 holds for one costless renegotiation. We then prove these results for a single costly renegotiation. As before, this step represents the base case of our proof by induction. In a second step, the inductive step, we will show that if debt is decreasing in the renegotiation thresholds for $n-1$ costly renegotiations, then it is also decreasing in the renegotiation thresholds for $n$ renegotiations. We will then proceed similarly for the coupon reduction given by Lemma 4 . This will complete our proof of both lemmas.

One costless renegotiation. We know from Eq. (6) that the debt value is given by:

$$
D\left(V, c, V_{S}, c^{\prime}, V_{B}^{\prime}\right)=\frac{c}{r}\left(1-\left(\frac{V}{V_{S}}\right)^{-X}\right)+d\left(V_{S}, c^{\prime}, V_{B}^{\prime}\right)\left(\frac{V}{V_{S}}\right)^{-X}
$$

where $V_{B}^{\prime}=\frac{(1-\tau) c^{\prime}}{r} \frac{X}{1+X}$ and $c^{\prime}$ is a function of $V_{S}$.

Differentiating with respect to $V_{S}$ we obtain:

$$
\frac{d D}{d V_{S}}=\underbrace{\frac{\partial D}{\partial V_{S}}}_{\text {direct effect }}+\underbrace{\frac{\partial D}{\partial c^{\prime}} \frac{\partial c^{\prime}}{\partial V_{S}}}_{\text {indirect effect }} .
$$

But we know that when creditors have all bargaining power, they choose $c^{\prime}$ to maximize $d\left(V_{S}, c^{\prime}, V_{B}^{\prime}\right)$. We can observe that Eq. (6) implies that $c^{\prime}$ also maximizes $D\left(V, c, V_{S}, c^{\prime}, V_{B}^{\prime}\right)$. Therefore, the indirect effect of $V_{S}$ on debt value is zero since $\frac{\partial D}{\partial c^{\prime}}=0$.

We then obtain:

$$
\frac{d D}{d V_{S}}=\frac{\partial D}{\partial V_{S}}=\left(\frac{V}{V_{S}}\right)^{-X} \frac{X}{V_{S}}\left(\frac{c^{\prime}-c}{r}\right)<0 .
$$

We have shown that debt is decreasing in the renegotiation threshold, creditors want to renegotiate at late as possible at $V_{S}=V_{B}$.

To show that $c^{\prime} / c=\phi_{1}$, we use the fact that $c^{\prime}$ is chosen to maximize $d\left(V_{S}, c^{\prime}, V_{B}^{\prime}\right)$. Using the first order condition we obtain:

$$
c^{\prime}=\frac{V_{S}}{A[X+1-(1-\alpha)(1-\tau) X]^{1 / X}}=\frac{V_{S}}{A R^{1 / X}} .
$$

We know that $V_{S}=V_{B}=A c$, therefore we obtain: $\frac{c^{\prime}}{c}=\frac{1}{R^{1 / X}}=\phi_{1}$, which proves Lemma 4 for the case of one costless renegotiation. 
One costly renegotiation. As in the case of equity, adding renegotiation costs will reinforce our results. Due to space constraints we omit the proof.

Multiple renegotiations. We now continue with the inductive step of the proof for multiple costless renegotiations. Adding renegotiation costs to multiple renegotiations will only reinforce our results. We assume that Lemma 3 and Lemma 4 hold for $n-1$ renegotiations. We then prove that they also hold for $n$ renegotiations.

Since we are using the backward recursive technique, assuming the two lemmas hold for $n-1$ renegotiations implies that for all $i \in\{2, \ldots, n\}$ debt is decreasing in the renegotiation thresholds, thus $V_{S_{i}}=V_{B}\left(c_{i-1}\right), \frac{c_{i}}{c_{i-1}}=\phi_{i}$, where $\phi_{i}$ is given by Eq. (13). In order to show that they also hold for $n$ renegotiations, we need to prove that debt at time zero is a decreasing function of $V_{S_{1}}$, thus $V_{S_{1}}=V_{B}(c)$ and $\frac{c_{1}}{c}=\phi_{1}$.

As we know by assumption that for all $i \in\{2, \ldots, n\}, V_{S_{i}}=V_{B}\left(c_{i-1}\right)$ and $\frac{c_{i}}{c_{i-1}}=\phi_{i}$, debt value at time zero can be expressed as a function of only two variables $V_{S_{1}}$ and $c_{1}$.

As in the case of one renegotiation, the indirect effect that $V_{S_{1}}$ has on debt value is zero since the coupon $c_{1}$ is chosen to maximize debt value. The total derivative of debt value with respect to $V_{S_{1}}$ will be equal to the partial derivative:

$$
\frac{d D}{d V_{S_{1}}}=\frac{\partial D}{\partial V_{S_{1}}}=\left(\frac{V}{V_{S_{1}}}\right)^{-X} \frac{X}{V_{S_{1}}}\left(\frac{c_{1}-c}{r}\right)<0 .
$$

It is optimal for the creditors to set $V_{S_{1}}=V_{B}=A c$. In order to show that the optimal coupon reduction is $c_{1} / c=\phi_{1}$ with $\phi_{1}$ given by Eq. (13), we will compute $c_{1}$ by maximizing $D\left(V_{S_{1}}, c_{1}, n-1\right)$. From the first order condition (knowing that for all $i \in\{2, \ldots, n\}, V_{S_{i}}=V_{B}\left(c_{i-1}\right)$ and $\frac{c_{i}}{c_{i-1}}=\phi_{i}$ ) we obtain:

$$
\begin{aligned}
c_{1}= & \frac{V_{S_{1}}}{A}\left[( X + 1 ) \left[1-\phi_{2}\left(1-\phi_{2}^{X}\right)-\phi_{2}^{X+1} \phi_{3}\left(1-\phi_{3}^{X}\right)\right.\right. \\
& \left.-\ldots-\left(\phi_{2} \phi_{3} \ldots \phi_{n-1}\right)^{X+1} \phi_{n}\left(1-\phi_{n}^{X}\right)\right] \\
& \left.-(1-\alpha)(1-\tau) X\left(\phi_{2} \ldots \phi_{n}\right)^{X+1}\right]^{-1 / X} .
\end{aligned}
$$

Replacing $V_{S_{1}}=V_{B}=A c$ we obtain $c_{1} / c=\phi_{1}$, where $\phi_{1}$ is given by Eq. (13). This completes the proof.

Proof of Lemma 5. We know from the previous proof, that for one single renegotiation the derivative of debt with respect to $V_{S}$ is:

$$
\frac{d D}{d V_{S}}=\underbrace{\frac{\partial D}{\partial V_{S}}}_{\text {direct effect }}+\underbrace{\frac{\partial D}{\partial c^{\prime}} \frac{\partial c^{\prime}}{\partial V_{S}}}_{\text {indirect effect }} .
$$

On the one hand, when the creditors choose the reduced coupon to maximize their debt value $\left(c_{\max }^{\prime}\right)$, we know that the indirect effect of $V_{S}$ on debt value is zero since $\frac{\partial D}{\partial c^{\prime}}=0$. Furthermore, the direct effect is negative. Therefore, the total effect is negative as well.

On the other hand, at the other extreme, for a reduced coupon $c_{\min }^{\prime}$, creditors are indifferent between renegotiating or not since the debt value stays constant at renegotiation. So the negative indirect effect cancels out with the positive direct effect.

We know that the coupon $C_{K_{i}}$, that makes the equity holder indifferent between renegotiating or not, is between the minimum reduced coupon and the maximum reduced coupon. Therefore, given a well behaved debt function, the total effect should be negative for any coupon value in between this interval, and then debt is a decreasing function of the renegotiation threshold.

Proof of Lemma 6. We know that the new reduced coupon $C_{K_{i}}$ is defined such that the equity surplus of renegotiation is exactly equal to the renegotiation cost. Therefore, at each stage $i$ we have:

$$
E\left(V_{B_{i-1}}, c_{i}, n-i\right)=K
$$

since we know that $V_{S_{i}}=V_{B_{i-1}}$. 
As at each renegotiation stage the coupon is chosen such that the equity holder's surplus is exactly equal to the renegotiation costs $K$, the equity holder will not win anything from all future renegotiations. Thus we have that $E\left(V_{B_{i-1}}, c_{i}, n-i\right)=E\left(V_{B_{i-1}}, c_{i}, 0\right)=e\left(V_{B_{i-1}}, c_{i}, V_{B_{i}}\right)$.

The equation then becomes:

$$
V_{B_{i-1}}-\frac{(1-\tau) c_{i}}{r}\left(1-\left(\frac{V_{B_{i-1}}}{V_{B_{i}}}\right)^{-X}\right)-V_{B_{i}}\left(\frac{V_{B_{i-1}}}{V_{B_{i}}}\right)^{-X}=K .
$$

Replacing $V_{B_{i}}=\frac{c_{i}(1-\tau) X}{r(X+1)}, V_{B_{i-1}}=\frac{c_{i-1}(1-\tau) X}{r(X+1)}$, multiplying by $\frac{r(X+1)}{1-\tau}$ and rearranging we obtain Eq. (18).

\section{References}

Alderson, M.J., Betker, B.L., 1999. Assessing postbankruptcy performance: An analysis of reorganized firms' cash flows. Financial Management $28,68-82$.

Anderson, R.W., Sundaresan, S., 1996. Design and valuation of debt contracts. Review of Financial Studies 9, 37-68.

Bai, Y., Zhang, J., 2012. Duration of sovereign debt renegotiation. Journal of International Economics 86, 252-268.

Bris, A., Welch, I., Zhu, N., 2006. The costs of bankruptcy: Chapter 7 liquidation versus Chapter 11 reorganization. Journal of Finance 61, 1253-1303.

Bruche, M., Naqvi, H., 2010. A structural model of debt pricing with creditor-determined liquidation. Journal of Economic Dynamics and Control 34, 951-967.

Chen, N., 2003. Chapter 11, private workouts and corporate debt pricing under asymmetric information. Working paper, Columbia University.

Daniels, K.N., Hurtado, F.D., Ramrez, G.G., 2013. An empirical investigation of corporate bond clawbacks (IPOCs): Debt renegotiation versus exercising the clawback option. Journal of Corporate Finance 20, 14-21.

Dumitrescu, A., 2007. Valuation of defaultable bonds and debt restructuring. Journal of Corporate Finance 13, 94-111.

Fan, H., Sundaresan, S.M., 2000. Debt valuation, renegotiation, and optimal dividend policy. Review of Financial Studies 13, $1057-1099$.

Favara, G., Schroth, E., Valta, P., 2012. Strategic default and equity risk across countries. Journal of Finance 67, 2051-2095.

Fischer, E.O., Heinkel, R., Zechner, J., 1989. Dynamic capital structure choice: Theory and tests. Journal of Finance 44, 19-40.

François, P., Morellec, E., 2004. Capital structure and asset prices: Some effects of bankruptcy procedures. The Journal of Business 77, 387-412.

Franks, J.R., Torous, W.N., 1989. An empirical investigation of U.S. firms in reorganization. Journal of Finance 44, 747-769.

Garleanu, N., Zwiebel, J., 2009. Design and renegotiation of debt covenants. Review of Financial Studies , 749-781.

Gilson, S.C., 1997. Transactions costs and capital structure choice: Evidence from financially distressed firms. Journal of Finance 52, $161-196$.

Gilson, S.C., John, K., Lang, L.H.P., 1990. Troubled debt restructurings: An empirical study of private reorganization of firms in default. Journal of Financial Economics 27, 315-353.

Hackbarth, D., Hennessy, C.A., Leland, H.E., 2007. Can the trade-off theory explain debt structure? Review of Financial Studies 20, 1389-1428.

Hege, U., Mella-Barral, P., 2000. Bargaining power and optimal leverage. Finance 21, 85-101.

Hege, U., Mella-Barral, P., 2005. Repeated dilution of diffusely held debt. The Journal of Business 78, 737-786.

Hotchkiss, E.S., 1995. Postbankruptcy performance and management turnover. Journal of Finance 50, 3-21.

Lambrecht, B.M., 2001. The impact of debt financing on entry and exit in a duopoly. Review of Financial Studies 14, $765-804$.

Leland, H.E., 1994. Corporate debt value, bond covenants, and optimal capital structure. Journal of Finance 49, $1213-1252$.

Longstaff, F.A., 1990. Pricing options with extendible maturities: Analysis and applications. Journal of Finance 45, $935-957$.

LoPucki, L.M., William C., W., 1993. Patterns in the bankruptcy reorganization of large, publicly held companies. Cornell Law Review 78, 597-618.

Mella-Barral, P., 1995. Optimal debt exchange offers. Discussion Paper- IRES, Université Catholique de Louvain.

Mella-Barral, P., 1999. The dynamics of default and debt reorganization. Review of Financial Studies 12, 535-578.

Mella-Barral, P., Perraudin, W., 1997. Strategic debt service. Journal of Finance 52, 531-556.

Moraux, F., 2002. Valuing corporate liabilities when the default threshold is not an absorbing barrier. Working paper, Université de Rennes 1.

Roberts, M., 2010. The role of dynamic renegotiation and asymmetric information in financial contracting. Working paper, University of Pennsylvania.

Roberts, M.R., Sufi, A., 2009. Renegotiation of financial contracts: Evidence from private credit agreements. Journal of Financial Economics 93, 159-184.

Shibata, T., Tian, Y., 2010. Reorganization strategies and securities valuation under asymmetric information. International Review of Economics \& Finance 19, 412-426.

Shibata, T., Tian, Y., 2012. Debt reorganization strategies with complete verification under information asymmetry. International Review of Economics \& Finance 22, 141-160.

Sturzenegger, F., Zettelmeyer, J., 2007. Debt defaults and lessons from a decade of crises. volume 1 of MIT Press Books. The MIT Press.

Suter, C., 1992. Debt cycles in the world-economy: Foreign loans, financial crises, and debt settlements, 1820-1990. Westview, Boulder, CO. 